Supporting Information (SI) to accompany:

\title{
Synergistic effect of high frequency ultrasound with cupric-oxide catalyst resulting in a selectivity switch in glucose oxidation under argon
}

Prince N. Amaniampong ${ }^{\mathrm{f}[\mathrm{a}]}$, Quang Thang Trinh ${ }^{\mathrm{f}[\mathrm{b}, \mathrm{c}]}$, Karine De Oliveira Vigier [d], Duy Quang Dao [c], Ngoc Han Tran ${ }^{[e]}$, Yingqiao Wang ${ }^{[\mathrm{f}]}$, Matthew P. Sherburne $*[\mathrm{f}, \mathrm{g}]$ and François Jérôme $*[\mathrm{a}, \mathrm{d}]$

a CNRS Research federation INCREASE, 1 rue Marcel Doré, TSA 41105, 86073 Poitiers (France)

${ }^{\mathrm{b}}$ Cambridge Centre for Advanced Research and Education in Singapore (CARES), Campus for Research Excellence and Technological Enterprise (CREATE), 1 Create Way, Singapore 138602 (Singapore)

${ }^{\mathrm{c}}$ Institute of Research and Development, Duy Tan University, 03 Quang Trung, Danang 550000 (Viet Nam).

d Institut de Chimie des Milieux et Matériaux de Poitiers (IC2MP), Université de Poitiers, CNRS, 1 rue Marcel Doré, TSA 41105, 86073 Poitiers (France).

e NUS Environmental Research Institute, National University of Singapore, 5A Engineering Drive 1, T-Lab Building, Singapore 117411 (Singapore)

${ }_{\mathrm{f}}^{\mathrm{f}}$ Materials Science and Engineering Department, University of California, Berkeley, Berkeley, California 94720 (United States of America).

g A Singapore Berkeley Research Initiative for Sustainable Energy, Berkeley Educational Alliance for Research in Singapore (BEARS), 1 CREATE Way, 138602 Singapore.

${ }^{\ddagger}$ These authors contributed equally: Prince Nana Amaniampong, Quang Thang Trinh. 


\section{Table of contents}

1. X-ray diffraction analysis of $\mathrm{CuO}$ samples $\quad \mathrm{S} 3$

2. X-ray photoelectron spectroscopic analysis $\quad$ S4

$\begin{array}{lll}\text { 3. X-ray diffraction analysis of regenerated spent } \mathrm{CuO} & \mathrm{S} 7\end{array}$

4. Effect of $\mathrm{CuO}$ catalyst loading on glucose oxidation under HFUS S8

5. Sonocatalytic conversion of fructose over $\mathrm{CuO}$ catalyst $\quad \mathrm{S} 9$

6. SEM and TEM characterizations of the fresh and spent $\mathrm{CuO}$ catalysts $\quad \mathrm{S} 10$

$\begin{array}{ll}\text { 7. Product/crude reaction characterization } & \text { S11 }\end{array}$

8. ${ }^{13} \mathrm{C}-\mathrm{NMR}$ of the crude reaction product in $d_{6}$-DMSO $\quad \mathrm{S} 12$

9. ${ }^{13} \mathrm{C}$-NMR of standard D-Glucuronic acid in $d_{6}$-DMSO $\quad \mathrm{S} 13$

10. HPLC analysis of pure standards and the crude reaction product $\quad$ S14

11. HPLC analysis of the crude reaction product using $\mathrm{CuO}_{\mathrm{HFUS}}$ as a catalyst $\quad \mathrm{S} 15$

$\begin{array}{ll}\text { 12. FT-IR spectra of the crude reaction product } & \text { S16 }\end{array}$

13. Computational details to study glucose activation and conversion $\begin{array}{ll}\text { on } \mathrm{CuO}(111) \text { surface } & \mathrm{S} 17\end{array}$

14. Adsorption and conversion of glucose on bare $\mathrm{CuO}(111)$ surface $\quad$ S20

15. Adsorption and conversion of glucose on $\mathrm{CuO}(111)$ $\begin{array}{ll}\text { with surface Hydroxyl OH ( CuO-US surface) } & \text { S25 }\end{array}$

16. Micro-kinetic modelling study for glucose-ring opening on bare $\mathrm{CuO}(111)$ $\begin{array}{lr}\text { and under HFUS conditions } & \text { S29 }\end{array}$

$\begin{array}{ll}\text { 17. References } & \text { S34 }\end{array}$ 
1. X-ray diffraction analysis of $\mathrm{CuO}$ samples

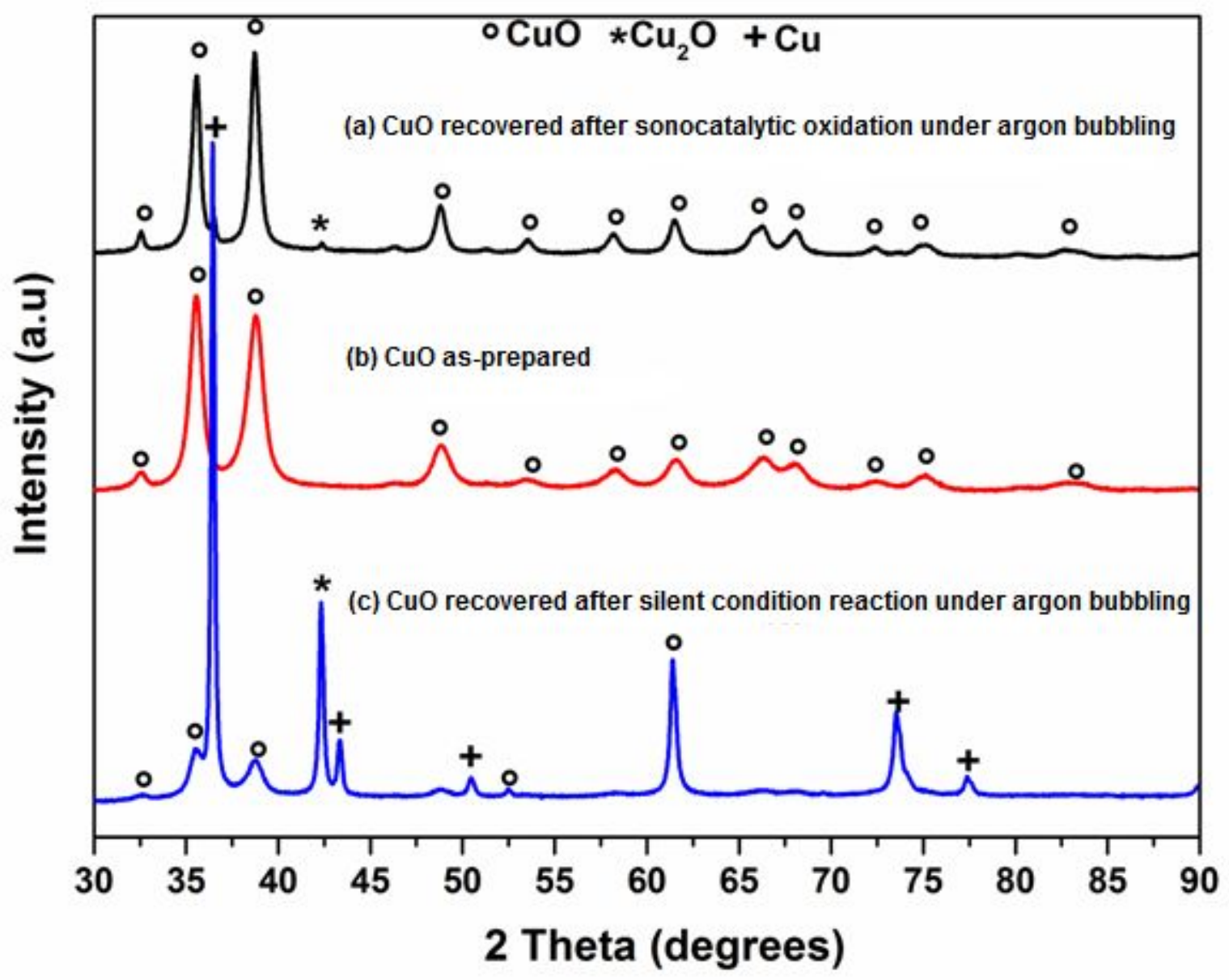

Figure S1. XRD analysis (a) $\mathrm{CuO}$ recovered after sonocatalytic oxidation under argon bubbling, (b) $\mathrm{CuO}$ as-prepared, (c) $\mathrm{CuO}$ recovered after silent condition reaction under argon bubbling 


\section{X-ray photoelectron spectroscopic analysis}

The additional peaks observed at $935.3,943.9$ and $941.3 \mathrm{eV}$ are due to the shakeup satellite peaks, and the analysis of the $\mathrm{Cu}$ LMM spectra revealed an intensity with kinetic energy of $917.1 \mathrm{eV}^{1}$ (Figure $\mathrm{S} 2 \mathrm{~b}$, characteristic of a $\mathrm{CuO}$ nano-structured material), and evidently ruling out the possibility of the existence of $\mathrm{Cu}_{2} \mathrm{O}$ phase. The $\mathrm{O} 1 \mathrm{~s}$ spectra of the synthesized $\mathrm{CuO}$ revealed distinctive peaks at 529-530 and 531-532 eV (Figure S3) attributed to the bulk lattice oxygen of $\mathrm{CuO}$ and surface adsorbed oxygen with low coordination, respectively. ${ }^{2-4}$ The high intensity at 531-532 eV suggests rich adsorbed dioxygen on the $\mathrm{CuO}$ surface. The peak centered at 533-534 eV corresponds to the water molecule, which confirms the formation of $\mathrm{CuO}$ in the hydrated form. ${ }^{5-6}$ 

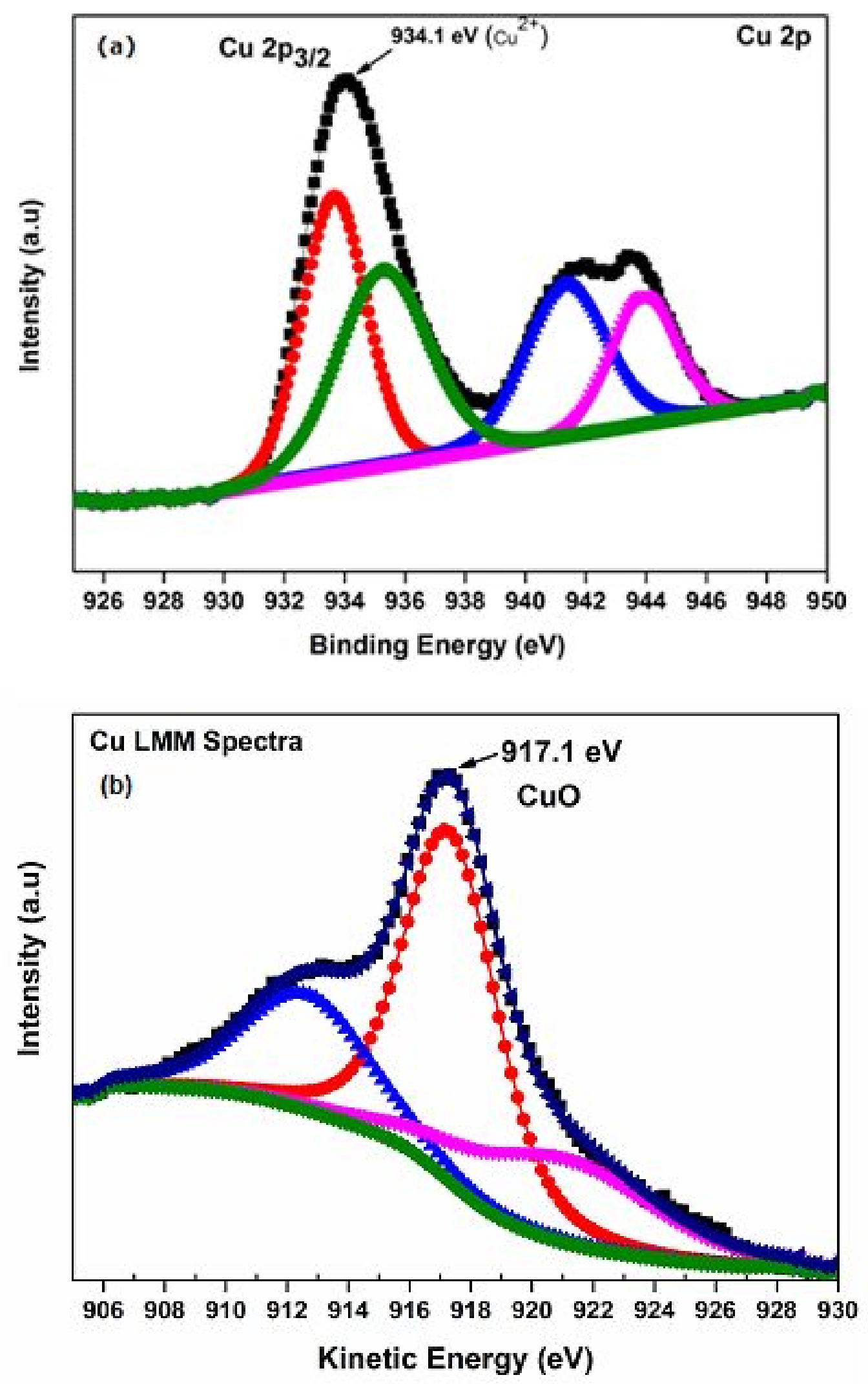

Figure S2. XPS analysis of $\mathrm{CuO}$ nanoleaves. (a) $\mathrm{Cu} \mathrm{p}_{3 / 2}$ peak fitting and (b) $\mathrm{Cu} \mathrm{LMM}$ analysis of the as-prepared $\mathrm{CuO}$ (US) 


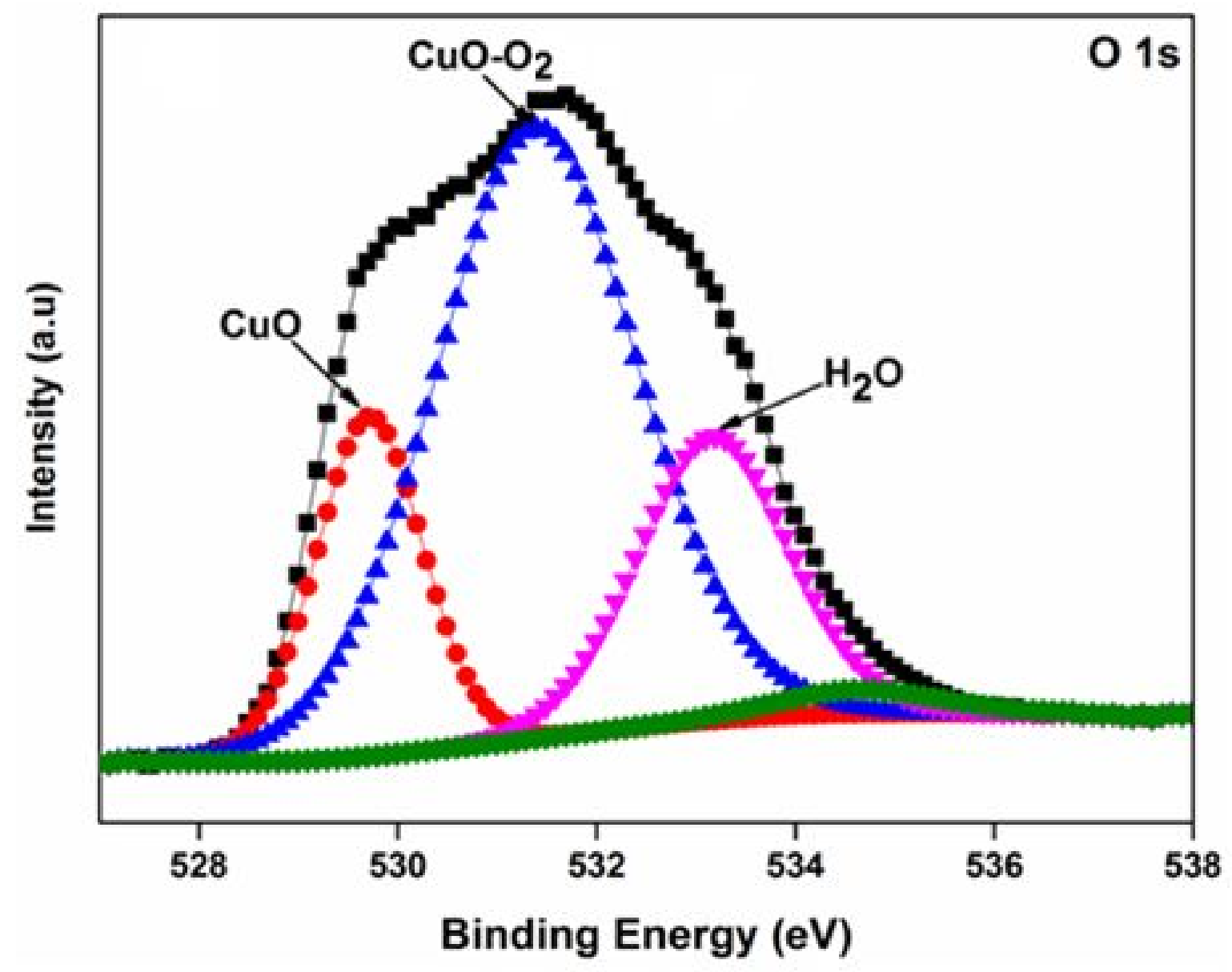

Figure S3. XPS analysis of O 1s peak fitting of $\mathrm{CuO}$ nanoleaves. 


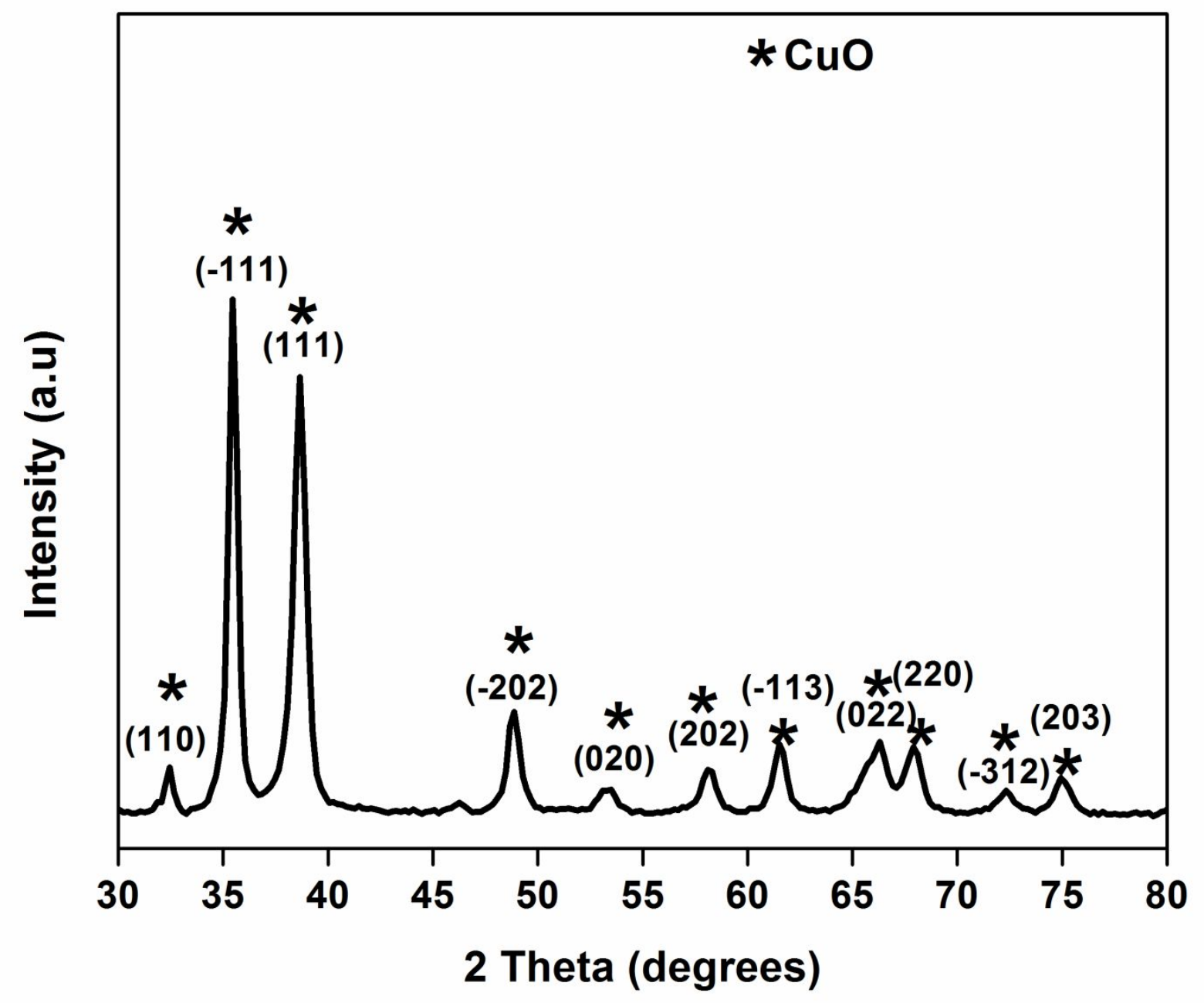

Figure S4. XRD analysis of $\mathrm{CuO}$ catalyst recovered after reaction at silent conditions and oxidized by high frequency ultrasound irradiation conditions in water and under argon bubbling 
4. Effect of $\mathrm{CuO}$ catalyst loading on glucose oxidation under HFUS

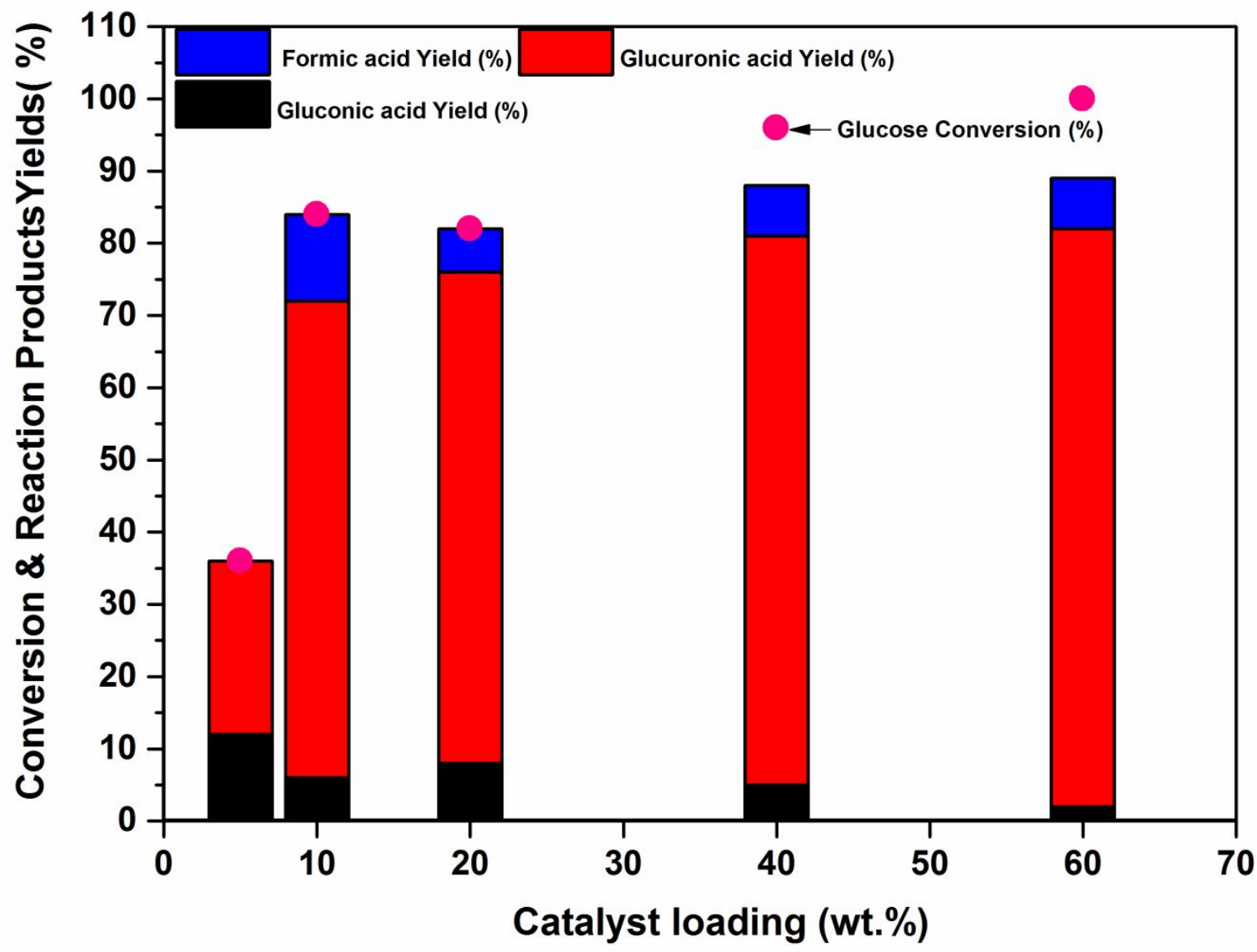

Figure S5. Effect of $\mathrm{CuO}$ catalyst amount on glucose oxidation under HFUS 
5. Sonocatalytic conversion of fructose over $\mathrm{CuO}$ catalyst

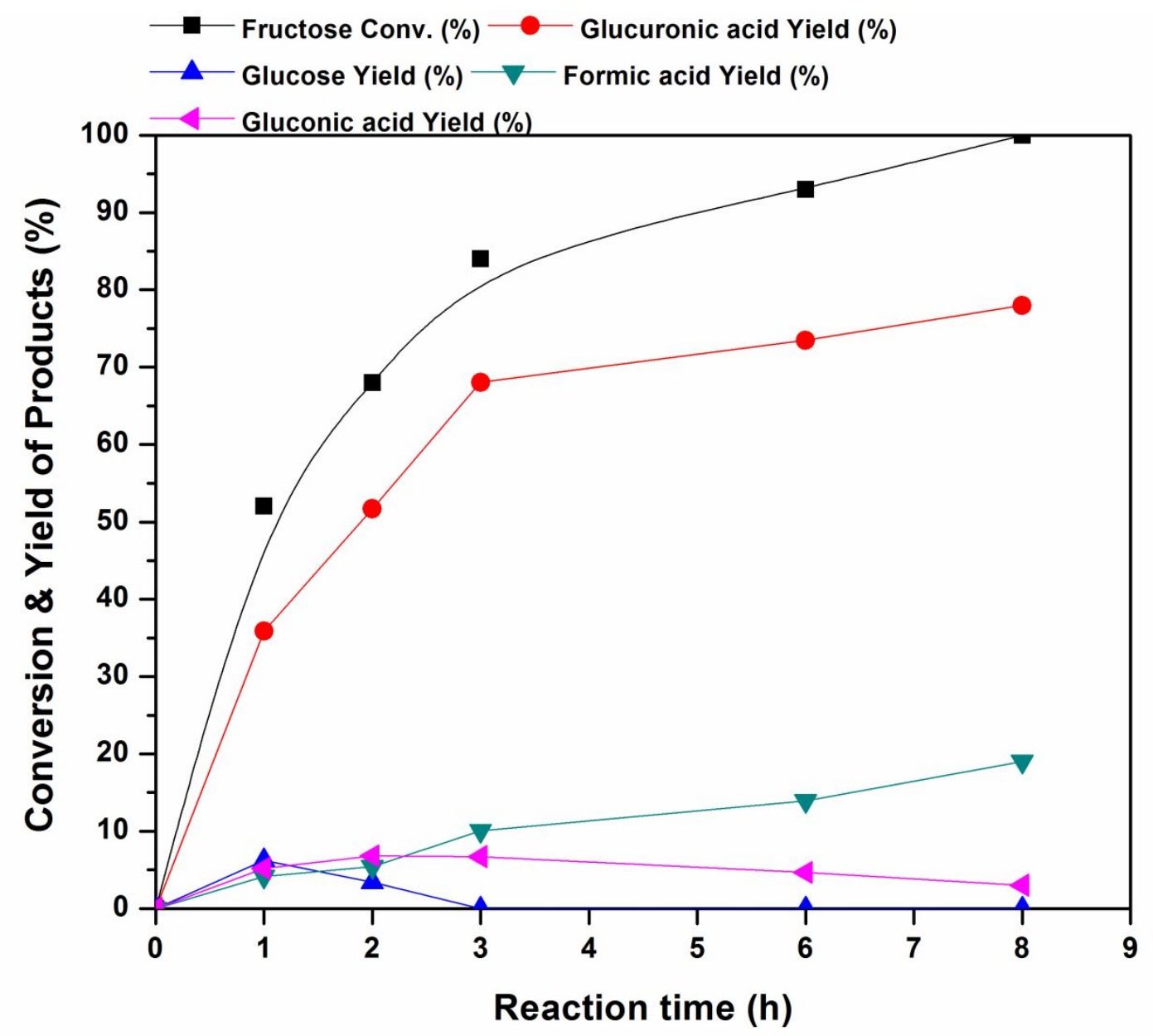

Figure S6. Kinetic profile of fructose oxidation over $\mathrm{CuO}$ catalyst under HFUS irradiation (10 $\mathrm{wt} \% \mathrm{CuO}, 80^{\circ} \mathrm{C}, 550 \mathrm{kHz}$ ). 


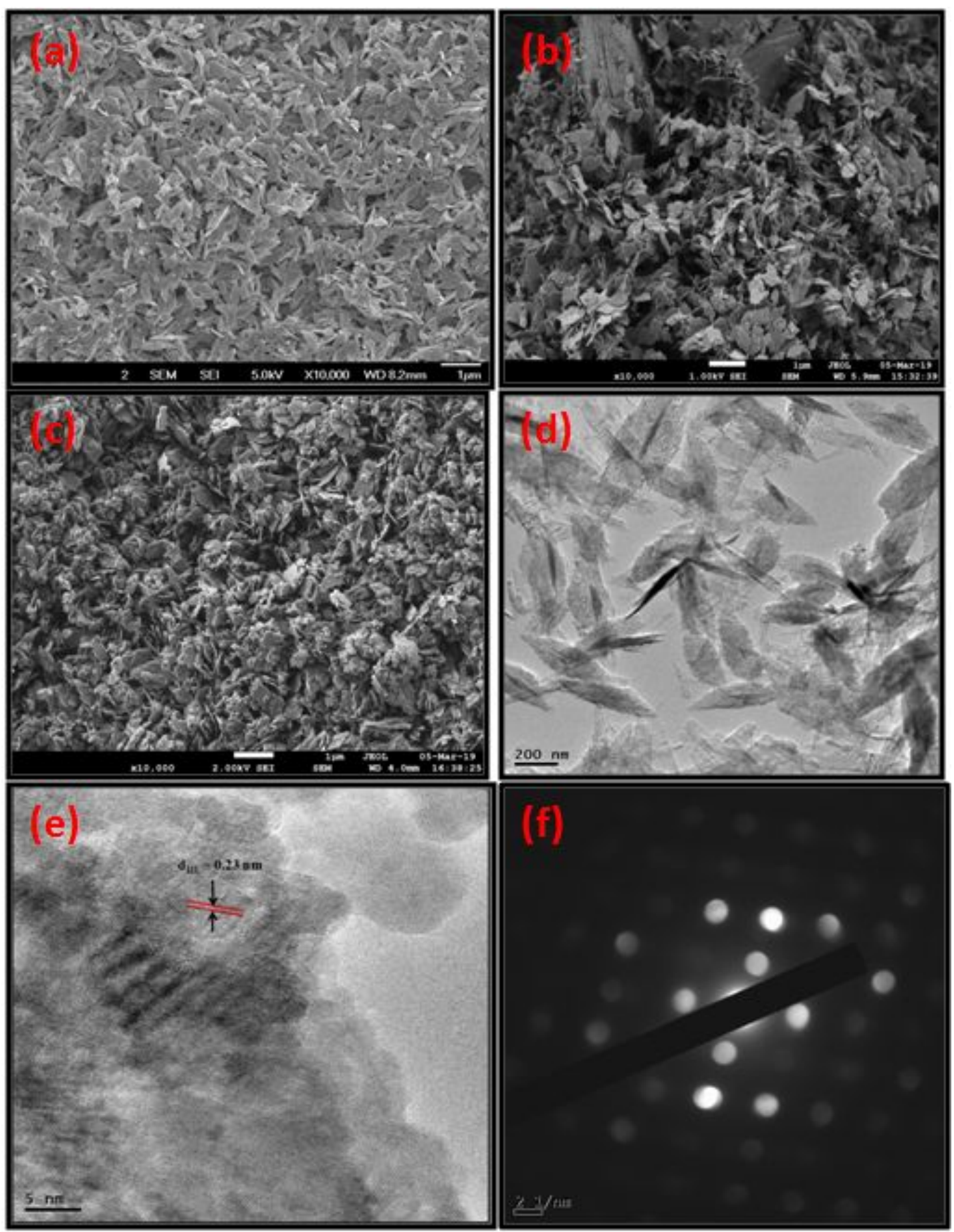

Figure S7. (a) SEM image of CuO catalyst synthesis by LFUS (b) SEM image of CuO catalyst synthesis by HFUS (c) Spent CuO-HFUS catalyst recovered after reaction (d) TEM image of CuO-HFUS catalyst (e) HRTEM of $\mathrm{CuO}$ showing lattice fringes of $\mathrm{CuO}$ with a lattice spacing of $0.23 \mathrm{~nm}$ (f) SAED pattern of $\mathrm{CuO}$ nanoleave catalyst 


\section{Product/crude reaction characterization}

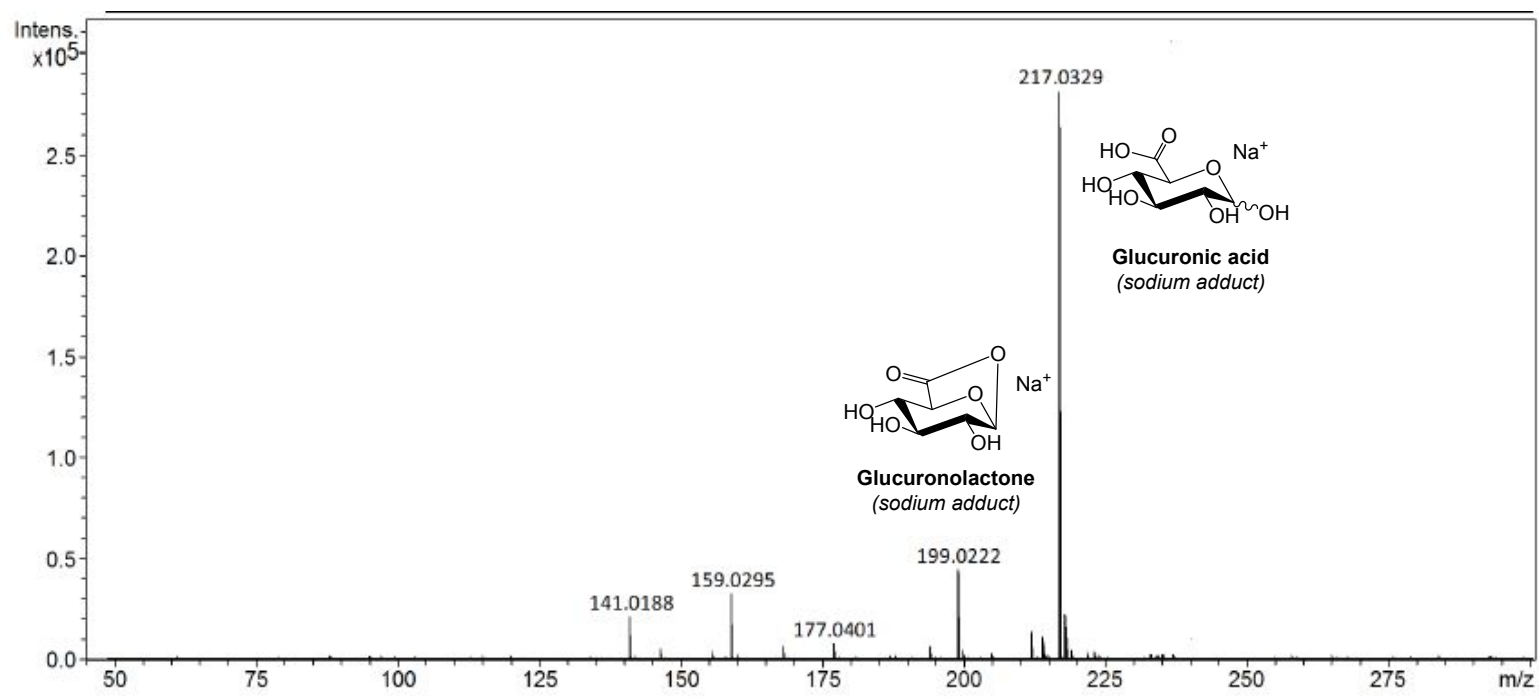

Figure S8. ESI-MS of reaction product 


\section{8. ${ }^{13} \mathrm{C}$-NMR of the crude reaction product in $d_{6}$-DMSO}

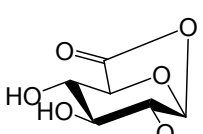

(A)

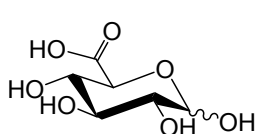

(B)

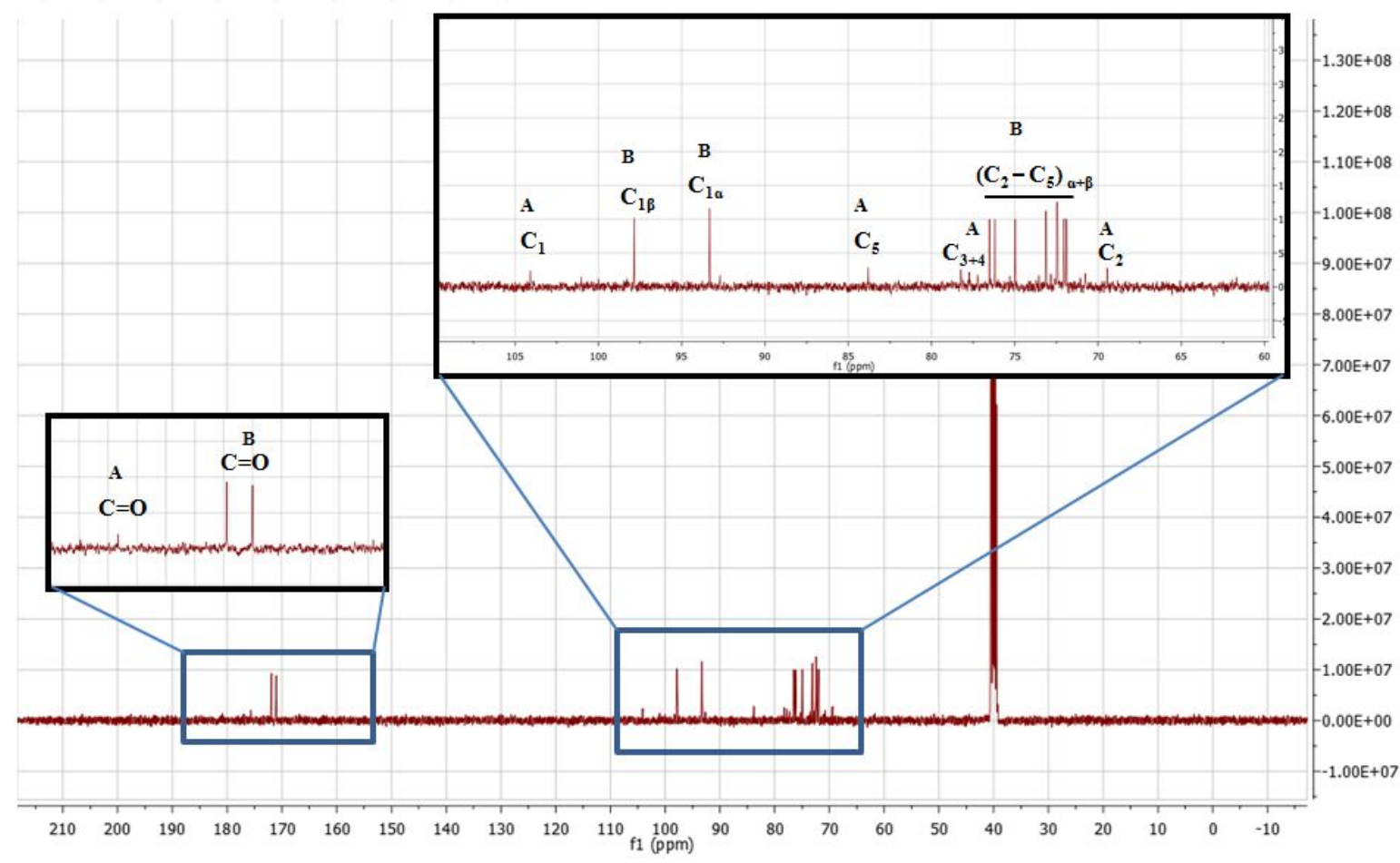

Figure S9a. ${ }^{13} \mathrm{C}$-NMR of the crude reaction product in $d_{6}$-DMSO (mixture of two anomers: $\alpha$ and $\beta$ ) 


\section{9. ${ }^{13} \mathrm{C}-\mathrm{NMR}$ of standard D-Glucuronic acid in $\boldsymbol{d}_{6}$-DMSO}

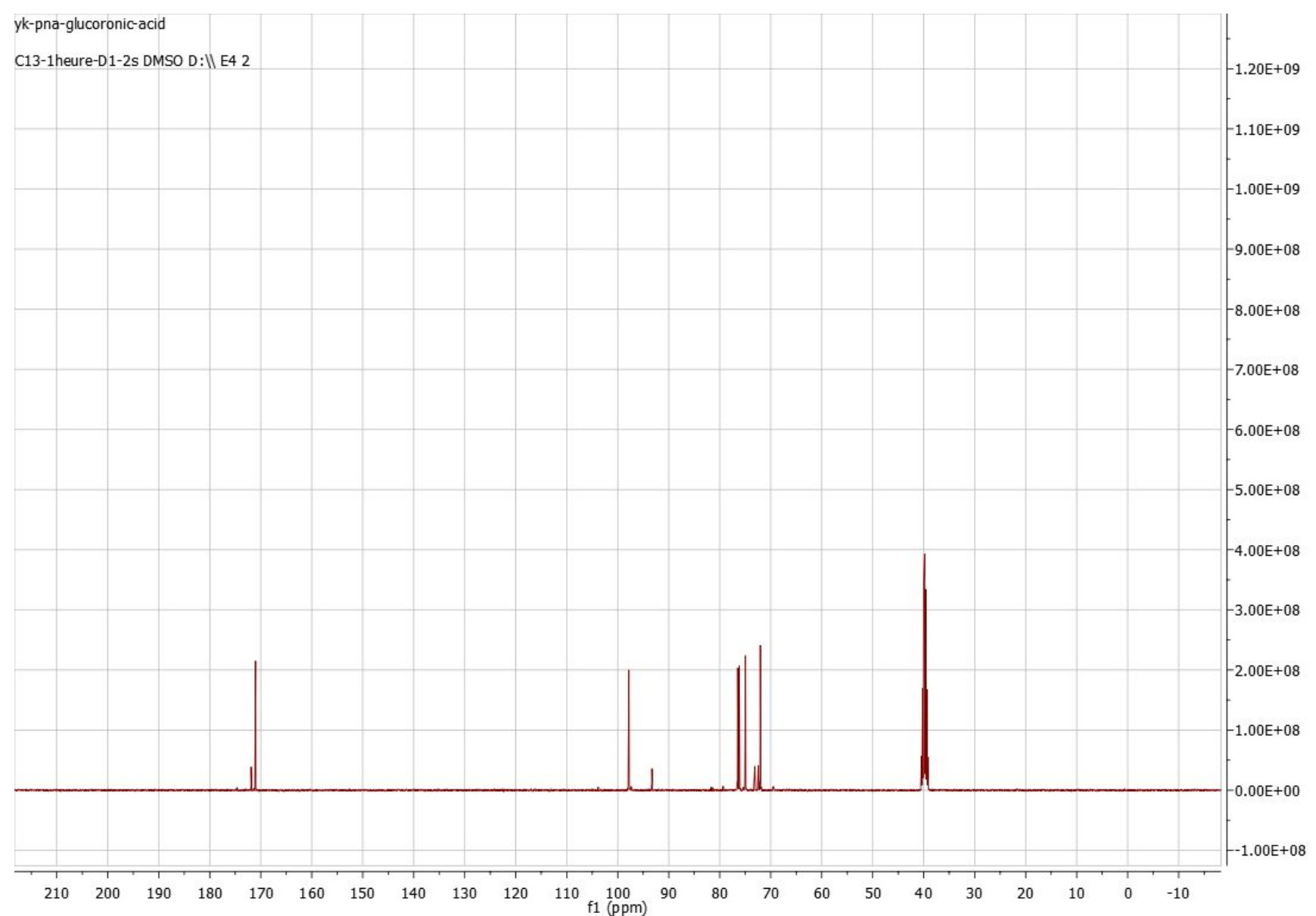

Figure S9b. ${ }^{13} \mathrm{C}$-NMR of standard D-Glucuronic acid in $d_{6}$-DMSO 
10. HPLC analysis of pure standards and the crude reaction product

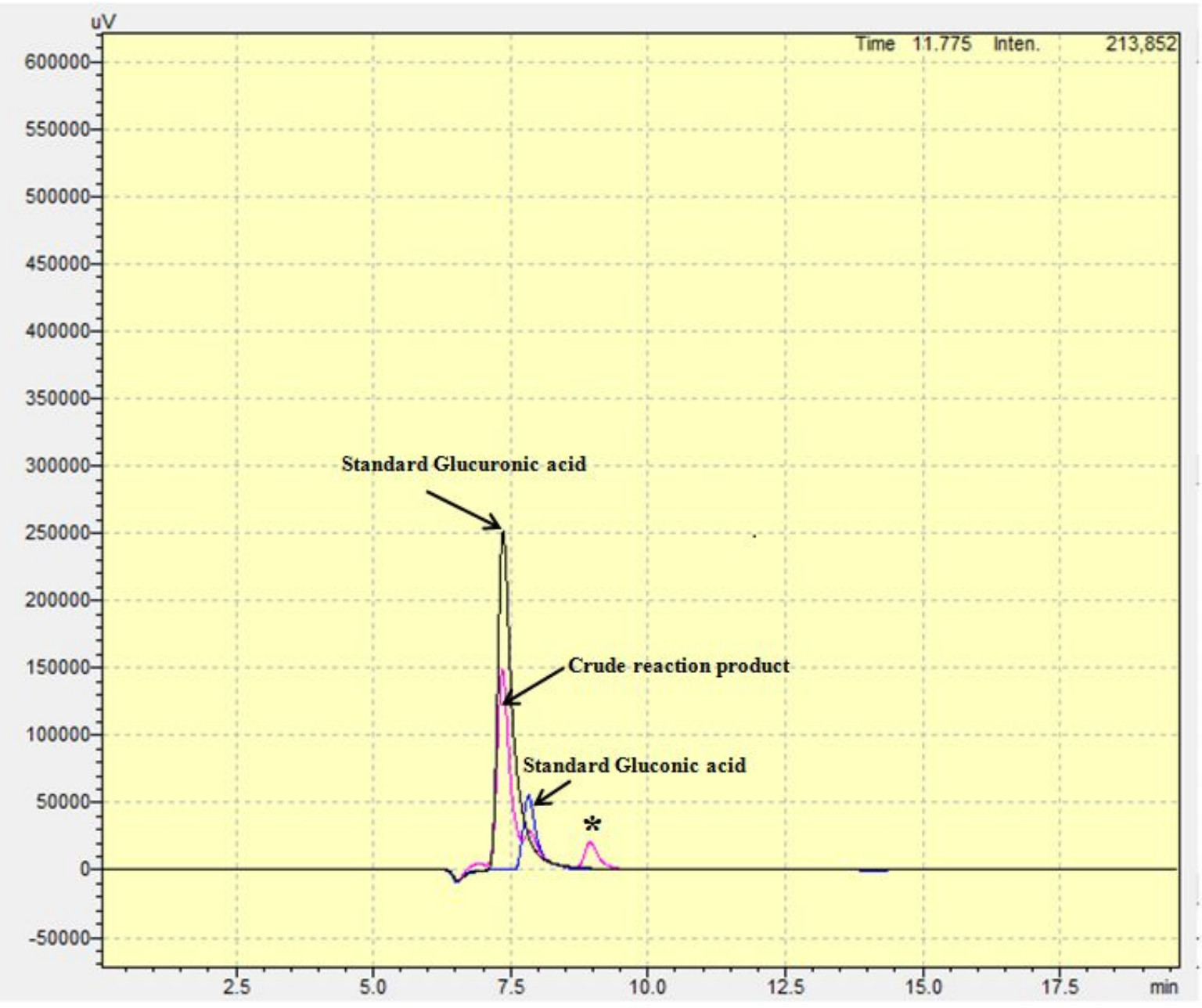

Figure S10a. HPLC analysis of pure standards (glucuronic acid (black) and gluconic acid (blue)) and the crude reaction product (pink), $550 \mathrm{kHz}, 80^{\circ} \mathrm{C}, 10 \mathrm{wt} \% \mathrm{CuO}, 6 \mathrm{~h}$ ).

*Glucurolactone was formed after lyophilization of crude reaction product only. 
11. HPLC analysis of the crude reaction product using $\mathrm{CuO}_{\mathrm{HFUS}}$ as a catalyst

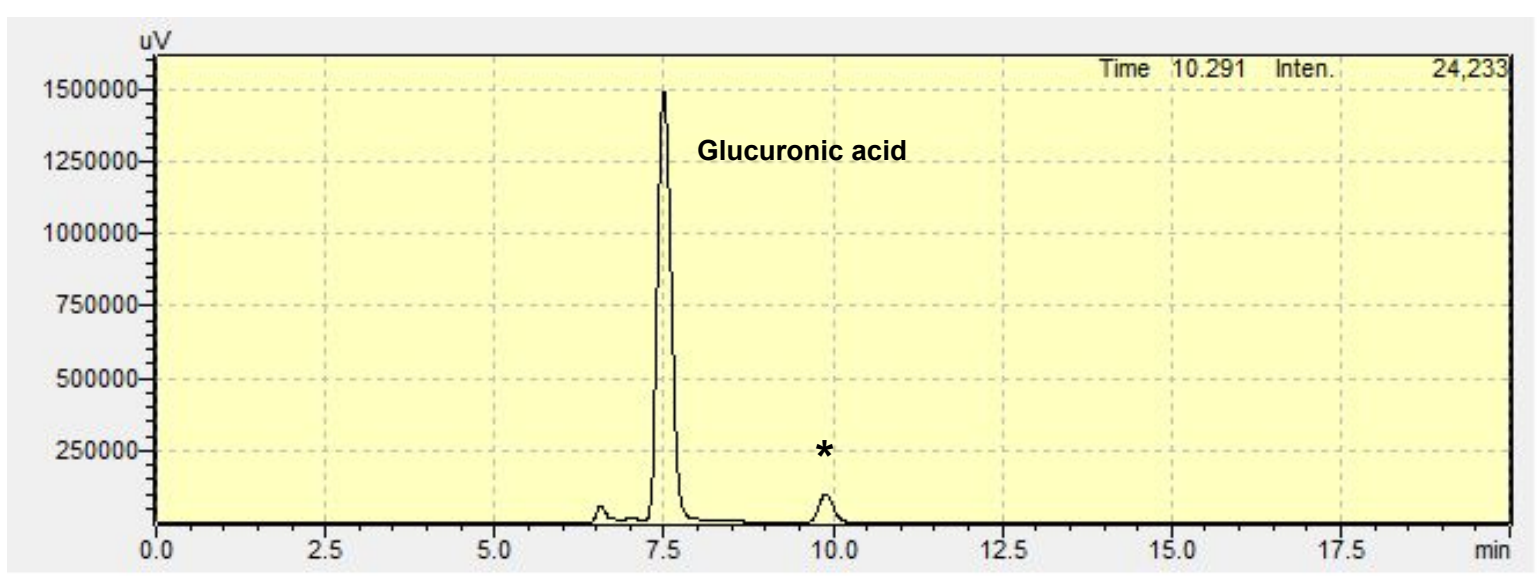

Figure S10b. HPLC analysis of the crude reaction product using $\mathrm{CuO}_{\mathrm{HFUS}}$ as a catalyst (550 $\left.\mathrm{kHz}, 80^{\circ} \mathrm{C}, 10 \mathrm{wt} \% \mathrm{CuO}_{\mathrm{HFUS}}, 6 \mathrm{~h}\right) *$ glucuronolactone was formed after lyophilization of crude reaction product only. Compared to Fig. S9b, there is a shift of $+0.4 \mathrm{~min}$ in the retention time due to a change of the ICE-COREGEL 107H column. 
12. FT-IR spectra of the crude reaction product

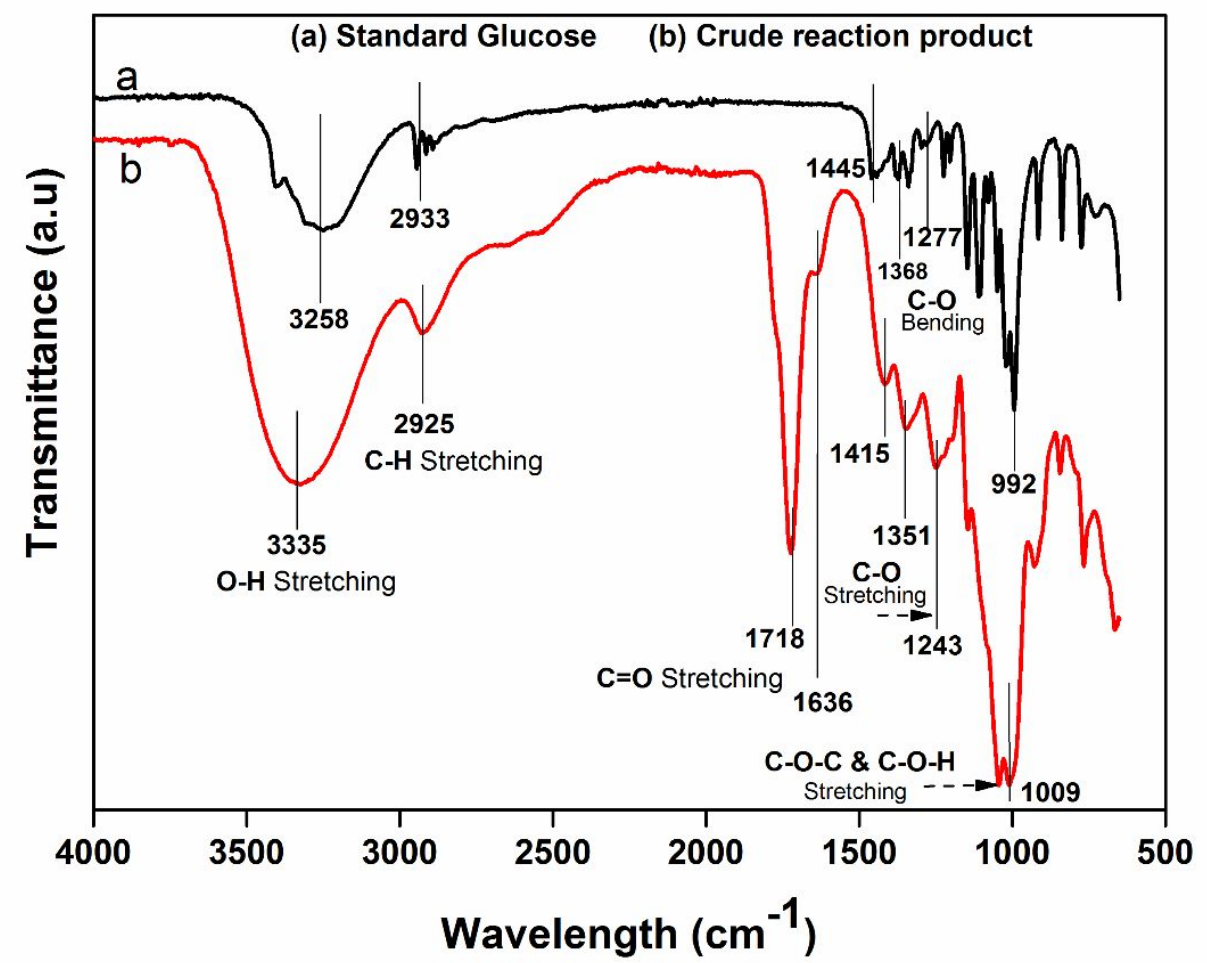

Figure S11. FT-IR spectra of the crude reaction product (red) $\left(550 \mathrm{kHz}, 80^{\circ} \mathrm{C}, 10 \mathrm{wt} \%\right.$ $\mathrm{CuO}_{\text {HFUS }}, 6 \mathrm{~h}$ ). 


\section{Computational details to study glucose activation and conversion on $\mathrm{CuO}(111)$ surface}

All first-principle calculations for adsorption and reactions on $\mathrm{CuO}(111)$ surface are performed based on periodic boundary conditions and plane-wave pseudopotential implementation of DFT using the Vienna ab-initio simulation package (VASP) developed at the Fakultät für Physik of the Universität Wien. ${ }^{7-8}$ Projector augmented wave (PAW) method ${ }^{9}$ employed with PerdewBurke-Ernzerhof (PBE) exchange-correlation functional ${ }^{10}$ are used to describe the interaction between valence electrons and ions with a plane wave cut-off energy of $450 \mathrm{eV}$. We used a kpoints sampling of $3 \times 3 \times 1$ with Monkhorst-pack scheme for integration over the Brillouin zone in reciprocal space and spin polarization is turned on for all simulations. The Generalized Gradient Approximation (GGA) and the Hubbard correction $\mathrm{U}=4.5 \mathrm{eV}$ within the GGA+U scheme was used to correct the electron delocalization that occurs in strongly correlated systems such as transition metal oxides. ${ }^{6,11-12}$ The optimized lattice parameters for $\mathrm{CuO}$ within $\mathrm{GGA}+\mathrm{U}$ are $\mathrm{a}=4.5597 \AA ; \mathrm{b}=3.6059 \AA ; \mathrm{c}=5.1782 \AA ; \beta=96.3385^{\circ}$, which also matches well with reported experimental data. ${ }^{13} \mathrm{CuO}$ catalyst is modeled by using the structure of $\mathrm{p}(4 \times 2)$ slab of the most stable $\mathrm{CuO}(111)$ surface with 4 layers and the vacuum thickness of $15 \AA$ above the topmost layer was employed to avoid interactions between repeted slabs. ${ }^{6}$ The bulk-like magnetic configuration was reported to be the most stable arrangement for $\mathrm{CuO}(111)$ surface, and therefore, was used for all calculations in this study. ${ }^{14}$ Geometries were fully relaxed using the conjugate-gradient algorithm until the energy changes by less than $0.1 \mathrm{~kJ} / \mathrm{mol}$. Transition states were located using the Climbing-Nudged Elastic Band (Cl-NEB) method, ${ }^{15}$ and frequency calculations confirmed the nature of the transition states with only one imaginary vibrational frequency.

In the studies of surface reactions on $\mathrm{CuO}$ surface, since all of the reactions in the energy profiles presented in Figure 2 of the main text (glucose ring-opening process) and Figure 3 of the main text (glucose oxidation to glucuronic acid) are surface reactions, and the activation 
barriers reported in those energy profiles are referenced to the adsorbed state of glucose (due to the strong adsorption of glucose on $\mathrm{CuO}$ surface with $\mathrm{E}_{\mathrm{ads}}>100 \mathrm{~kJ} / \mathrm{mol}$, it is reasonable to use the adsorbed state of glucose on $\mathrm{CuO}$ surface as the reference point for the energy profiles), hence we expect the dispersion correction does not have a big impact in changing the activation barriers. Our earlier study has comprehensively compared the activation barriers and reaction energies for surface reactions with and without the dispersion correction for the decomposition of toluene on $\mathrm{Ni}(111)$ surface by using the PBE functional (without dispersion correction) and optB88-vdW functional (vdW interaction is inclusively integrated). ${ }^{16}$ The data in the mentioned study showed that the dispersion correction only had noticeable influence to the initial adsorption energy of reactants from gas phase onto the surface, but the effect of the dispersion correction to the reaction properties (activation barriers and reaction energies) for all subsequent surface reactions is small and could be neglected. To again validate it, we also performed the GGA+U calculations with the dispersion correction by using DFT-D3 method ${ }^{17}$ and the BeckeJonson (BJ) damping ${ }^{18}$ implemented in VASP for all reactions in Figure 2 of the main text (glucose ring-opening process). As expected, our observed data shows that the activation barriers computed with and without the dispersion correction only differ very slightly within $\pm 3 \mathrm{~kJ} / \mathrm{mol}$. It is very consistent with our earlier study mentioned above, wherein we reported that the inclusion of long-range interaction did not alter the activation barriers and reaction energies of surface reactions. ${ }^{16}$

Finally, since $\mathrm{CuO}$ is a semi-conductor and is a strongly correlated transition metal oxide, therefore to correctly describe the electron localization in this material, the Hubbard term correction implemented in the GGA+U scheme was applied in our computational method. The correction value $\mathrm{U}=4.5 \mathrm{eV}$ was appropriately chosen from our recent benchmarking studies using several different experimental surface sensitive techniques such as adsorption enthalpy measurement in combination with FT-IR analysis ${ }^{19}$ and XPS study. ${ }^{6}$ In those studies, the 
$\mathrm{GGA}+\mathrm{U}$ with the $\mathrm{U}=4.5 \mathrm{eV}$ describes accurately the adsorption energies of different adsorbates on $\mathrm{CuO}$ surface, e.g. $\mathrm{HO}^{\bullet}$ and $\mathrm{H}_{2} \mathrm{O} .{ }^{19}$ Besides, it also predicts the XPS binding energies for other adsorbates $\left(\mathrm{O}_{2}, \mathrm{H}_{2} \mathrm{O}, \mathrm{HCO}_{3} \ldots\right)$ in excellent agreement with experimental data. ${ }^{6}$ However, when the inclusion of dispersion correction was used within the GGA+U scheme, the performance of GGA $+U$ in describing some surface properties is worsen. For example, we calculated the XPS O1s binding energies for two well-characterized adsorbates on $\mathrm{CuO}$ surface, called the molecular adsorption of $\mathrm{O}_{2}$ and the adsorption of $\mathrm{H}_{2} \mathrm{O}$ at the oxygen vacancy site of $\mathrm{CuO}$. The XPS O1s binding energies for those structures were experimentally identified at $531.4 \mathrm{eV}$ and $533.2 \mathrm{eV}$, respectively. ${ }^{6,20}$ The comparison on the performance of GGA+U with and without the Grimme's D3 dispersion correction in predicting the XPS O1s binding energies of different adsorbates on $\mathrm{CuO}$ surface is shown in Table $\mathrm{T} 1$. Due to (i) the inclusion of dispersion correction only slightly changes the activation barriers for surface reactions and (ii) the performance of $\mathrm{GGA}+\mathrm{U}$ is worsen with the usage of dispersion correction, we therefore use the computed values without the dispersion correction in our manuscript.

Table T1. Computed XPS O1s binding energy (eV) for different adsorbates on $\mathrm{CuO}$ surface with and without the inclusion of dispersion correction.

\begin{tabular}{c|c|c|c|c}
\hline Adsorbate & Configuration & $\begin{array}{c}\text { With the dispersion } \\
\text { correction }\end{array}$ & $\begin{array}{c}\text { Without the } \\
\text { dispersion correction }\end{array}$ & $\begin{array}{c}\text { Experimental } \\
\text { data6, 20 }\end{array}$ \\
\hline $\begin{array}{c}\text { Adsorbed } \\
\text { molecular } \mathrm{O}_{2}\end{array}$ & 530.98 & 531.39 & 531.4 \\
\hline $\begin{array}{c}\text { Adsorbed } \\
\text { oxygen } \\
\text { vacancy }\end{array}$ & & 532.76 & & 533.2 \\
\hline
\end{tabular}




\section{Adsorption and conversion of glucose on bare $\mathrm{CuO}(111)$ surface}

\subsection{Adsorption of ring structure-glucose on bare $\mathrm{CuO(111)} \mathrm{surface}$}

Since more than $99 \%$ of glucose exists mainly in the cyclic form (called glucopyranose), the investigation of glucose adsorption on $\mathrm{CuO}(111)$ surface needs to consider the adsorption of the ring structure. ${ }^{21-22}$ Due to the saturated nature of the carbon atoms in the ring structure of glucose, glucose in its glucose-pyranose form only could be adsorbed on $\mathrm{CuO}$ via the bonding of its hydroxyl groups with the oxide surface. ${ }^{21}$ Different adsorption configurations and the corresponding adsorption energy of glucose on $\mathrm{CuO}(111)$ surface are presented in Figure $\mathrm{S} 12$.
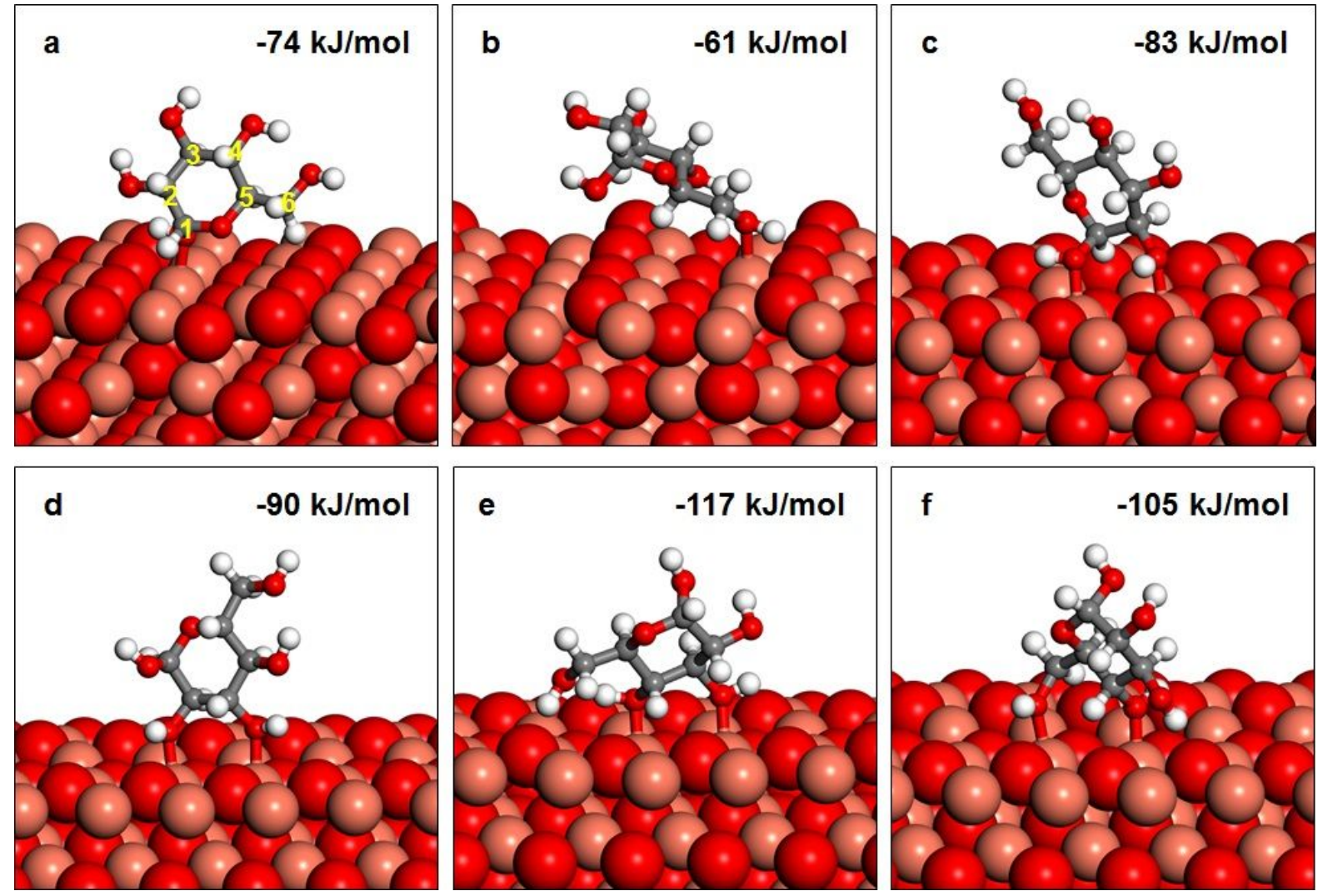

Figure S12. Different adsorption configurations of glycose in its pyranose form on $\mathrm{CuO}(111)$ surface. Glucose is coordinated to the surface via (a) a single $\mathrm{OH}$ attached to $\mathrm{C} 1$ position; (b) a single $\mathrm{OH}$ attached to $\mathrm{C} 6$ position; (c) two $\mathrm{OH}$ attached to $\mathrm{C} 1$ and $\mathrm{C} 2$; (d) two $\mathrm{OH}$ attached to $\mathrm{C} 2$ and $\mathrm{C} 3$; (e) two $\mathrm{OH}$ attached to $\mathrm{C} 3$ and $\mathrm{C} 4$ and (f) two $\mathrm{OH}$ attached to $\mathrm{C} 4$ and $\mathrm{C} 6$. Adsorption energies are inserted for the corresponding adsorption configuration and the Carbon atoms are numbered in (a). Color code: Large peach and red balls represent Copper (Cu) and Oxygen $(O)$ atoms of the $\mathrm{CuO}$ substrate; and small white, grey, and red balls represent Hydrogen $(H)$, Carbon $(C)$, and Oxygen $(O)$ atoms of the adsorbates, respectively. 
Generally, it could be seen in Fig. S12 that glucose adsorbs stronger via two hydroxyl group than via a single hydroxyl group. It should be noted that the computed adsorption energies for glucose when it coordinates to $\mathrm{CuO}$ via $\mathrm{OH}$ attached to $\mathrm{C} 1$ (Fig.S12a), $\mathrm{C} 2, \mathrm{C} 3$ and $\mathrm{C} 4$ positions of glucose are all similar, except the value at C6 position is slightly lower (Fig.S12b). In the strongest adsorption configurations, glucose is coordinated to $\mathrm{CuO}(111)$ surface via $\mathrm{OH}$ group attached to $\mathrm{C} 3$ and $\mathrm{C} 4$ groups and the corresponding adsorption energy is $-117 \mathrm{~kJ} / \mathrm{mol}$ (Fig.S12e).

\subsection{Ring-opening of glucose on bare $\mathrm{CuO}(111)$}

As it was mentioned in our earlier study, ${ }^{21}$ the adsorption and ring-opening of glucose on surface of heterogeneous catalyst might be an important factor that influence to the activity and selectivity of glucose conversion. Since in aqueous solution, glucose exits mostly in its glucopyranose form which is the close-ring structure, the ring opening process could be an important factor that determine the selectivity of the glucose oxidation, as is illustrated in Scheme Sc1. If the ring-opening is very feasible, the glucose oxidation will give the open-chain product (gluconic acid); and in the case the ring-opening is inhibited, the product of glucose oxidation will have the close-ring structure (glucuronic acid). 


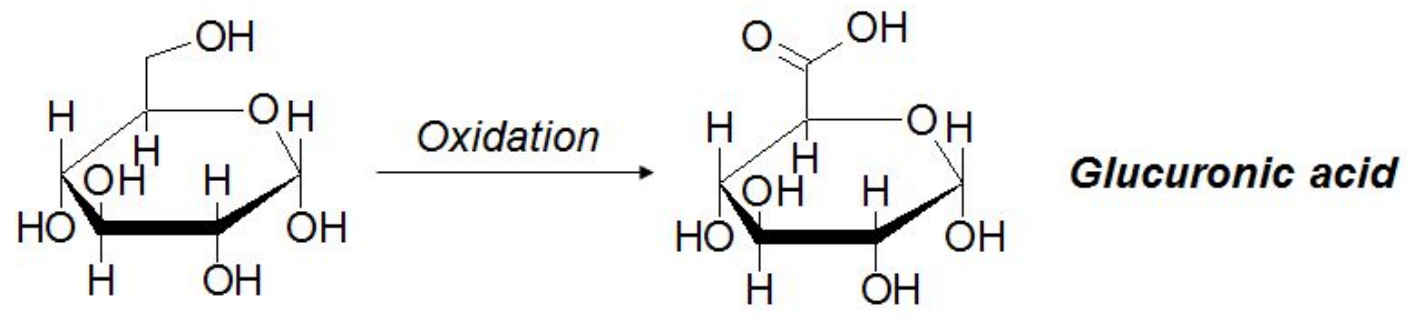
$\downarrow \uparrow \begin{aligned} & \text { Ring } \\ & \text { opening }\end{aligned}$<smiles>O=CC(O)C(O)C(O)C(O)CO</smiles><smiles>O=C(O)C(O)C(O)C(O)C(O)CO</smiles>

Scheme Sc1. Ring opening of glucose and different products of Glucose oxidation 
Table T2. Two steps of glucose ring-opening on bare $\mathrm{CuO}(11)$ surface

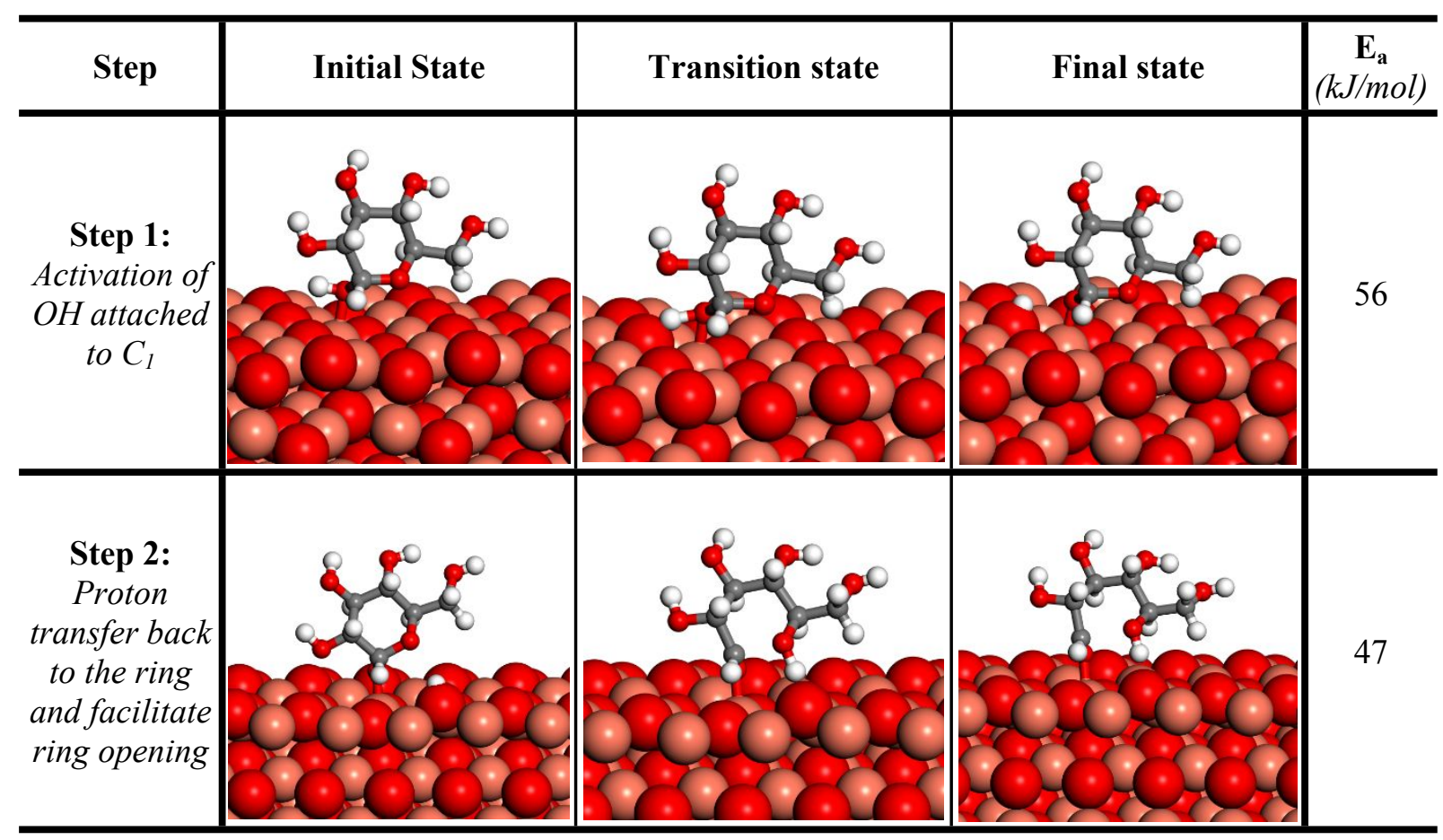

The process of glucose ring-opening on $\mathrm{CuO}(111)$ surface include two steps, where the hydrogen from the hydroxyl group attached to the $\mathrm{C} 1$ atom in the ring needs to be transferred to the ring oxygen. ${ }^{21,23-26}$ In the first step, the deprotonation of the $\mathrm{C} 1$ hydroxyl coordinated to the metal surface is studied, and the Initial state, transition state and final state for this step are shown in Table T2. The activation energy barrier $\mathrm{E}_{\mathrm{a}}$ for the deprotonation of the hydroxyl group attached to $\mathrm{C} 1$ on $\mathrm{CuO}(111)$ is $56 \mathrm{~kJ} / \mathrm{mol}$ (Table $\mathrm{S} 1$ ), which is quite feasible at reaction conditions. After the deprotonation, hydrogen generated from step 1 is transferred back to the ring oxygen atom of the glucose molecule to initiate the glucose ring opening. The initial, transition, and final states for the step 2 of the glucose ring opening on $\mathrm{CuO}(111)$ are shown in Table T2. The activation energy barrier for the ring opening is only $47 \mathrm{~kJ} / \mathrm{mol}$. It is important to note that the product, i.e., the open-chain glucose, is in the $\eta_{1}(\mathrm{O})$ configuration ${ }^{21}$ and this adsorption configuration exposes the aldehyde functional group of glucose, which later can be oxidized to gluconic acid using the lattice oxygen of $\mathrm{CuO}$ catalyst as was observed in our earlier experimental study. ${ }^{13,27}$ 


\subsection{Oxidation of glucose to glucuronic acid on bare $\mathrm{CuO(111)}$}

For the oxidation of glucose to glucuronic acid, the ring-structure of glucose need to be kept intact, while the $\mathrm{CH}_{2} \mathrm{OH}$ group (carbon at $\mathrm{C} 6$ position) is selectively oxidized. The reaction pathway for glucose oxidation to glucuronic acid is described and discussed in detailed in the main text, and the initial, transition and final states for the reactions are presented in Table T3.

Table T3. Oxidation of glucose to glucuronic acid on bare $\mathrm{CuO}(111)$ surface

\begin{tabular}{|c|c|c|c|c|}
\hline & Initial State & Transition state & Final state & $\begin{array}{c}\mathbf{E}_{\mathbf{a}} \\
(\mathrm{kJ} / \mathrm{mol})\end{array}$ \\
\hline $\begin{array}{c}\text { Step 1: } \\
\text { Activation of } \\
\text { OH attached } \\
\text { to C6 }\end{array}$ & & & & 45 \\
\hline $\begin{array}{c}\text { Step 2: } \\
\text { Subsequent } \\
\text { activation of } \\
\text { CH bond, } \\
\text { forming CHO } \\
\text { functional } \\
\text { group }\end{array}$ & & & & 83 \\
\hline $\begin{array}{l}\text { Step 3: } \\
\text { Formyl C-H } \\
\text { bond } \\
\text { activation, } \\
\text { prior to the } \\
\text { oxidation }\end{array}$ & & & & 153 \\
\hline
\end{tabular}

Initially, the $\mathrm{OH}$ attached to $\mathrm{C} 6$ position of glucose could be activated by the surface undercoordination lattice Oxygen of $\mathrm{CuO}^{3,28}$ with the activation barrier of $45 \mathrm{~kJ} / \mathrm{mol}$ (TS1-1, Fig.3 of the main text) as shown in step 1 of Table T3. Subsequently in step 2, the $\mathrm{CH}$ bond also could be dissociated with the barrier of $83 \mathrm{~kJ} / \mathrm{mol}$, forming the aldehyde compound. After that, the oxidation of the aldehyde group involve the breaking of the formyl $\mathrm{C}-\mathrm{H}$ bond, which was 
stated as the key step for the oxidation of aldehyde to its corresponding acid. ${ }^{13}$ This elementary reaction of formyl $\mathrm{C}-\mathrm{H}$ bond activation on $\mathrm{CuO}(111)$ surface has the very high barrier of 153 $\mathrm{kJ} / \mathrm{mol}$ (step 3, Table T3), hindering the oxidation of glucose to glucuronic acid, and it is very consistent with the low selectivity towards glucuronic acid observed for glucose oxidation on bare $\mathrm{CuO}$ catalyst. After the formyl $\mathrm{C}-\mathrm{H}$ bond has been activated, the incorporation of the lattice oxygen from $\mathrm{CuO}$ into the glucose molecule is energetically feasible (Fig. 3 of the main text), resulting in the formation of glucuronic acid as the final product.

\section{Adsorption and conversion of glucose on $\mathrm{CuO}(111)$ with surface $\mathrm{Hydroxyl} \mathrm{OH}$ ( $\mathrm{CuO}$ -}

\section{US surface)}

\subsection{Adsorption of glucose on CuO-US}

The adsorption energy for glucose adsorbed on $\mathrm{CuO}(111)$ covered by surface $\mathrm{OH}^{*}$ group is calculated using the equation: $E_{a d s}=E_{(\text {glucose }-O H) *}-\left(E_{\text {glucose }(\text { gas })}+E_{O H *}\right)$

whereas the $\mathrm{E}_{\text {(glucose-OH)* }}, \mathrm{E}_{\text {glucose (gas) }}$ and $\mathrm{E}_{\mathrm{OH}^{*}}$ are the computed total energies for the glucose co-adsorption with surface $\mathrm{OH}^{*}$, glucose in gas phase and surface $\mathrm{OH}^{*}$ on $\mathrm{CuO}(111)$, respectively.
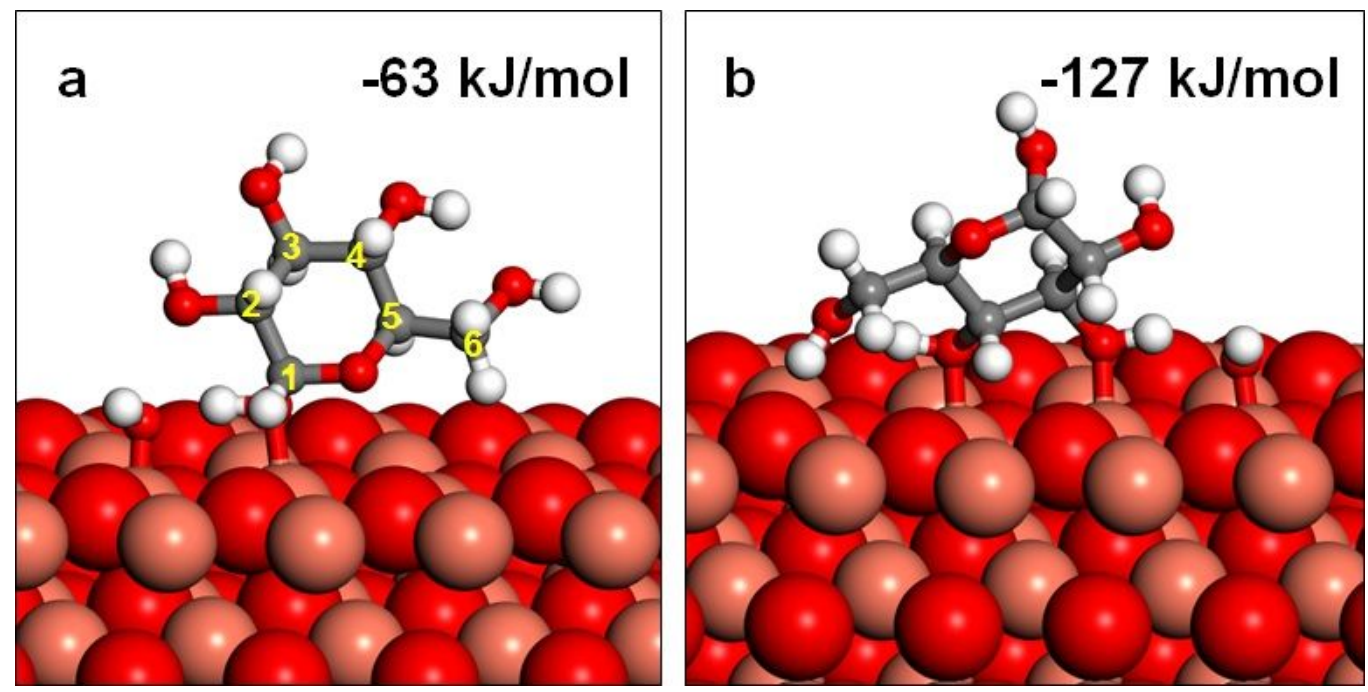

Figure S13. Different adsorption configurations of gluco-pyranose form on CuO-US surface. Glucose is coordinated to the surface via (a) a single $\mathrm{OH}$ attached to $\mathrm{C} 1$ position and (b) two 
$\mathrm{OH}$ attached to $\mathrm{C} 3$ and $\mathrm{C} 4$. Adsorption energies are inserted for the corresponding adsorption configuration and the Carbon atoms are numbered in (a). Color code is the same as Fig. S12. Generally, the trend for adsorption energies when glucose coordinates to CuO-US via different configurations is the same as it is on bare $\mathrm{CuO}(111)$ surface. However, if glucose adsorbs via only a single $\mathrm{OH}$ (i.e. via $\mathrm{OH}$ attached to $\mathrm{C} 1$ position, Fig.S13a), the computed adsorption energy is lower than it is on bare $\mathrm{CuO}(111)$. Oppositely, the computed adsorption energy when glucose coordinates to $\mathrm{CuO}-\mathrm{US}$ via two $\mathrm{OH}$ groups attached to $\mathrm{C} 3$ and $\mathrm{C} 4$ positions is -127 $\mathrm{kJ} / \mathrm{mol}$ (Fig. S13b), which is slightly higher than it is on bare $\mathrm{CuO}(111)$ surface (Fig.S12e).

\subsection{Ring-opening of glucose on CuO-US surface}

Table T4. Glucose ring-opening on $\mathrm{CuO}-\mathrm{US}$ surface

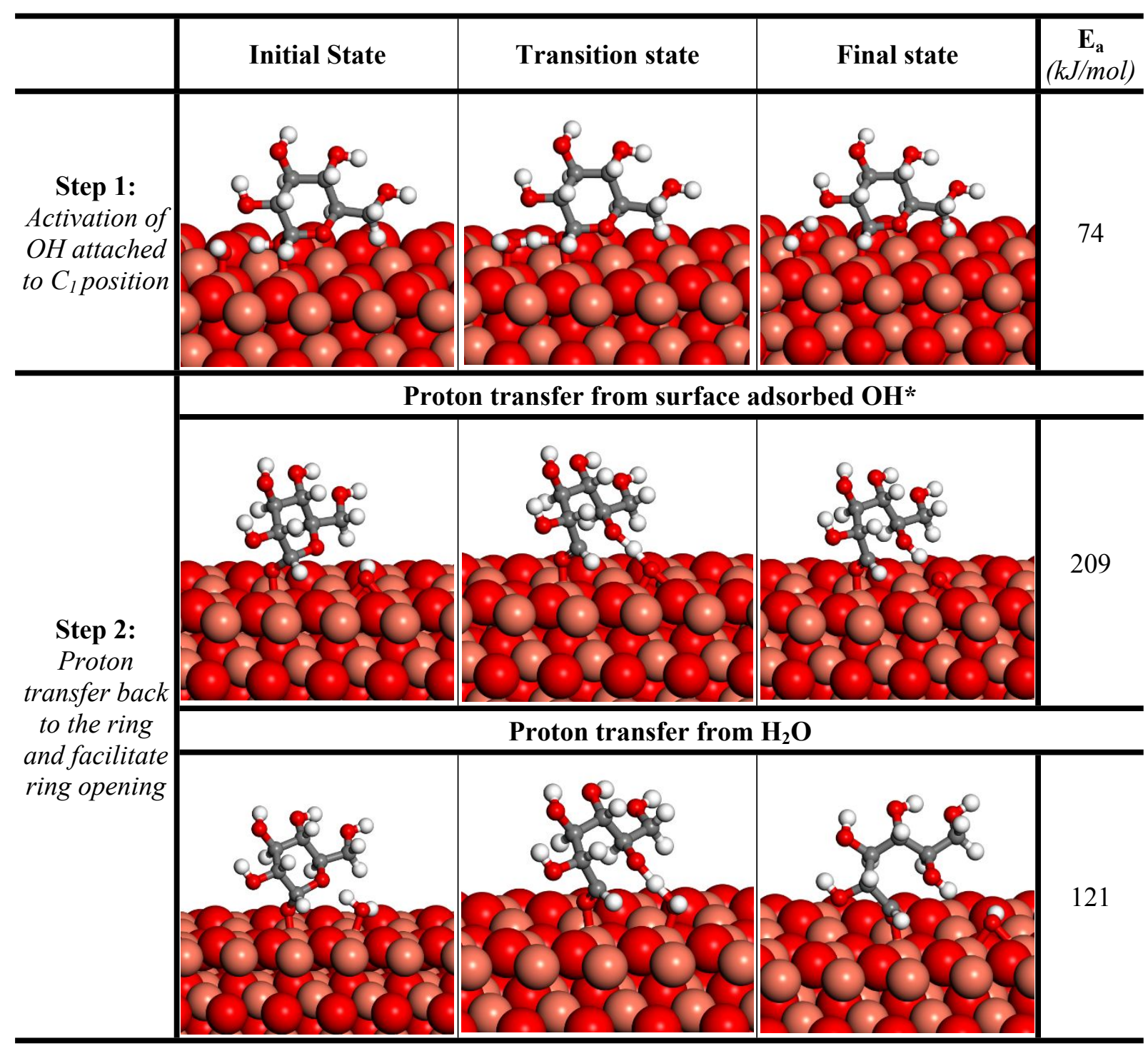


The ring opening of glucose on CuO-US also includes two steps and is presented in Table T4. The first step of the glucose ring-opening is the dehydrogenation of the hydroxyl attached to the $\mathrm{C}_{1}$ position, similarly to this step on bare $\mathrm{CuO}$ surface. However, the barrier for this step on $\mathrm{CuO}-\mathrm{US}$ is $17 \mathrm{~kJ} / \mathrm{mol}$ higher than it is on bare $\mathrm{CuO}(74 \mathrm{vs} 56 \mathrm{~kJ} / \mathrm{mol}$ on $\mathrm{CuO}-\mathrm{US}$ vs bare $\mathrm{CuO}$ surface, respectively). The reason for higher activation barrier on CuO-US might be due to the stabilization of Hydrogen-bonding between $\mathrm{OH}$ group of glucose and the surface $\mathrm{OH}$ adsorbed on $\mathrm{CuO}$ making glucose adsorbs stronger on $\mathrm{CuO}-\mathrm{US}$, therefore its activation is somehow more difficult. It is important to note that in the transition state, the $\mathrm{H}$ is being transferred "over the air" to the surface adsorbed $\mathrm{OH}$ group and results in the formation of $\mathrm{H}_{2} \mathrm{O}$ in the Final state (Step 1, Table T4). Therefore, to facilitate the ring-opening in step 2, the source of $\mathrm{H}$ to transfer back to the ring will be either from adsorbed surface $\mathrm{OH}$ or from adsorbed $\mathrm{H}_{2} \mathrm{O}$. The former pathway where the $\mathrm{H}$ atom from surface hydroxyl group is abstracted and transferred back to the ring has a very high barrier of $209 \mathrm{~kJ} / \mathrm{mol}$, which is $162 \mathrm{~kJ} / \mathrm{mol}$ higher than it is on bare $\mathrm{CuO}$ surface. If the hydrogen is abstracted from a surface adsorbed water molecule, the barrier is lower but still quite high with the value of $121 \mathrm{~kJ} / \mathrm{mol}$, and this reaction also suffers from additional entropic energy penalty to locate the water molecule at that specified position in the transition state $(\sim 50 \mathrm{~kJ} / \mathrm{mol})$, as reported by Gunasorria et al. ${ }^{29}$ These high barriers for both pathways in step 2 therefore, largely inhibit the ring-opening of glucose on $\mathrm{CuO}$ surface under HFUS conditions.

\subsection{Oxidation of glucose to glucuronic acid on CuO-US surface}

Differently from the conversion on bare $\mathrm{CuO}$ surface, the selective oxidation of glucose to glucuronic acid on $\mathrm{CuO}$ under HFUS conditions is much more feasible, and all initial, transition and final states for elementary reactions occurred during the conversion are shown in table T5. 
Table T5. Oxidation of glucose to glucuronic acid on CuO-US surface

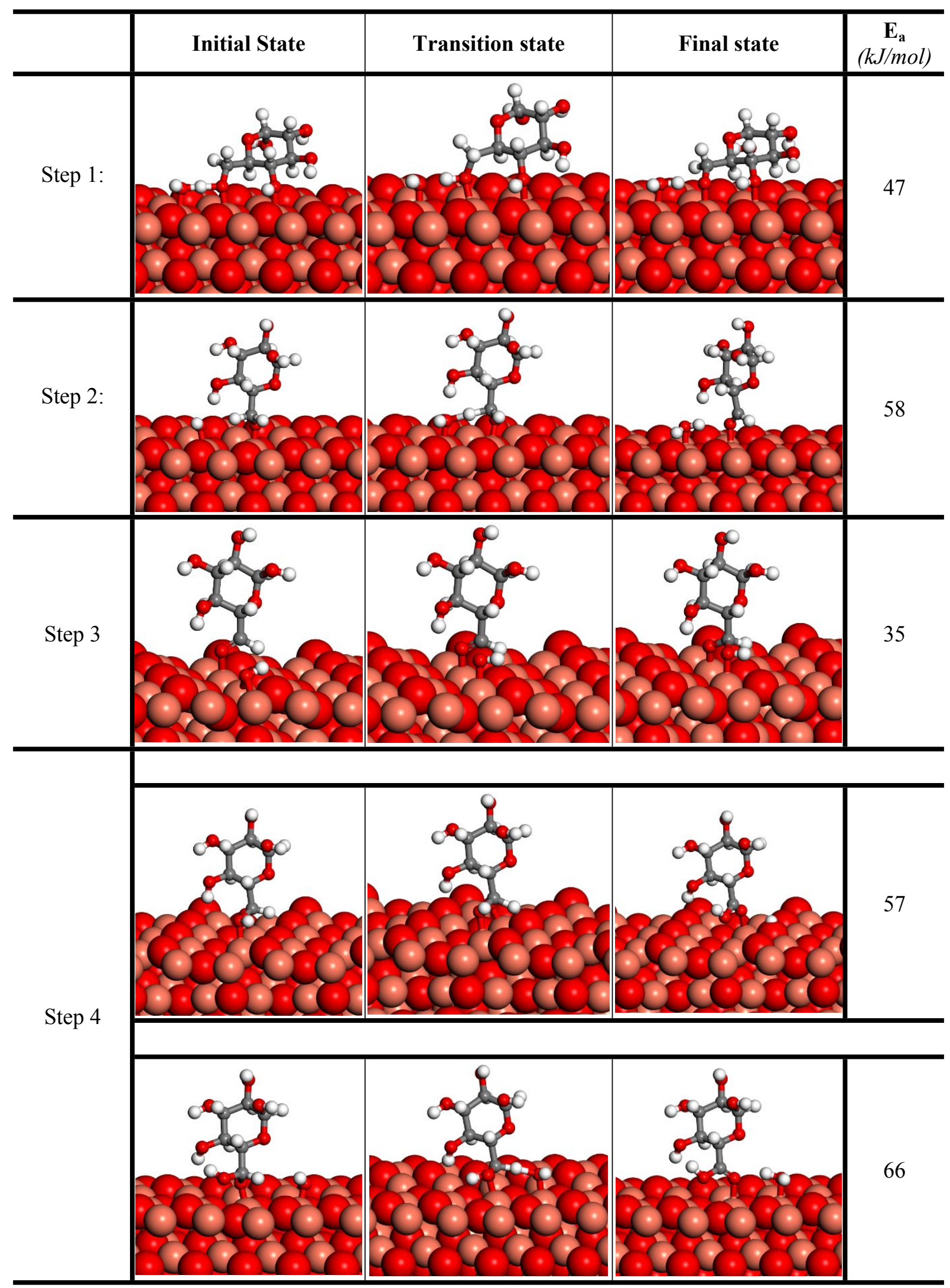


The process is also initiated with the activation of the hydroxyl attached to $\mathrm{C}_{6}$ position of glucose, facilitated by the surface adsorbed $\mathrm{OH}$ generated by ultrasound. The barrier for this pathway is $47 \mathrm{~kJ} / \mathrm{mol}$ (step 1, Table T5), comparable to the barrier of $45 \mathrm{~kJ} / \mathrm{mol}$ for the pathway facilitated by surface lattice oxygen on bare $\mathrm{CuO}$ surface (step 1, Table T3). However, the subsequent $\mathrm{CH}$ activation forming "glucose aldehyde" has the lower barrier of $58 \mathrm{~kJ} / \mathrm{mol}$ (step 2, table T5) compare to the barrier of $85 \mathrm{~kJ} / \mathrm{mol}$ for this reaction on bare $\mathrm{CuO}$ surface. Particularly, the next step involving the incorporation of surface adsorbed $\mathrm{OH}$ as oxidant into the "glucose aldehyde" has the barrier of only $35 \mathrm{~kJ} / \mathrm{mol}$, much lower than the barrier of 153 $\mathrm{kJ} / \mathrm{mol}$ for the formyl $\mathrm{C}-\mathrm{H}$ bond activation on bare $\mathrm{CuO}$ surface, making the oxidation to glucuronic acid on $\mathrm{CuO}$ under HFUS conditions much more feasible. The dissociation of $\mathrm{C}-\mathrm{H}$ bond of the complex formed in step 3 can be facilitated by surface lattice oxygen of $\mathrm{CuO}$ surface or by surface adsorbed $\mathrm{OH}$, with the former pathway is slightly more feasible. It could be seen that the presence of surface adsorbed OH generating under HFUS conditions has opened an alternative pathway for glucose oxidation to glucuronic acid in a lower barrier route, explaining the high selectivity of glucuronic acid observed on $\mathrm{CuO}$ under HFUS from experiment.

\section{Micro-kinetic modelling study for glucose-ring opening on bare $\mathrm{CuO}(111)$ and under HFUS conditions}

A micro-kinetic model is developed to study the glucose ring-opening on bare $\mathrm{CuO}$ surface and on $\mathrm{CuO}$ surface with high coverage of surface $\mathrm{OH}$ (called $\mathrm{CuO}-\mathrm{US}$ ), using adsorbed glucose as a starting point. 
Overall reactions:

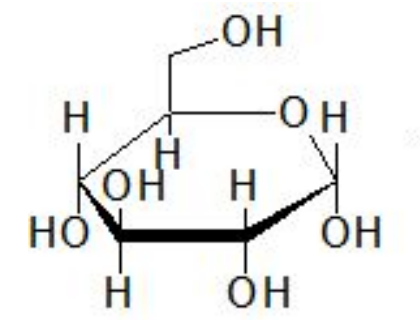

adsorbed $\mathrm{C}_{6} \mathrm{H}_{12} \mathrm{O}_{6}$ * (close-ring) $\leftrightarrow \quad$ adsorbed $\mathrm{C}_{6} \mathrm{H}_{12} \mathrm{O}_{6}$ * (open-chain)

We break down the overall reaction into a series of elementary reactions and express the rate of reaction in terms of surface coverage of species:

$$
\begin{aligned}
& \mathrm{C}_{6} \mathrm{H}_{12} \mathrm{O}_{6}(\mathrm{r})^{*}+* \quad \leftrightarrow \mathrm{C}_{6} \mathrm{H}_{11} \mathrm{O}_{6} *+\mathrm{H}^{*} \\
& r_{1}=k_{1 f} \theta_{C 6 H 1206(r) *} \theta_{*}-k_{1 r} \theta_{C 6 H 1106 *} \theta_{H *} \\
& \mathrm{C}_{6} \mathrm{H}_{11} \mathrm{O}_{6} *+\mathrm{H}^{*} \quad \leftrightarrow \mathrm{C}_{6} \mathrm{H}_{12} \mathrm{O}_{6}(\mathrm{o})^{*}+* \\
& r_{2}=k_{2 f} \theta_{C 6 H 1106 *} \theta_{H *}-k_{2 r} \theta_{C 6 H 1206(o) *} \theta_{*}
\end{aligned}
$$

On bare $\mathrm{CuO}$, the surface species include * (surface active site); $\mathrm{H}^{*}$ and three intermediates $\mathrm{C}_{6} \mathrm{H}_{12} \mathrm{O}_{6}(\mathrm{r}) *$ (adsorbed glucose in its ring structure); $\mathrm{C}_{6} \mathrm{H}_{11} \mathrm{O}_{6} * ; \mathrm{C}_{6} \mathrm{H}_{12} \mathrm{O}_{6}$ (o) ${ }^{*}$ (adsorbed glucose in its open-chain structure)

Therefore, the ODE equations governing the surface coverages of species on bare $\mathrm{CuO}$ are:

$\frac{d \theta_{C 6 H 1206(r) *}}{d t}=-r_{1}=-k_{1 f} \theta_{C 6 H 1206(r) *} \theta_{*}+k_{1 r} \theta_{C 6 H 1106 *} \theta_{H *}$

$\frac{d \theta_{C 6 H 1106 *}}{d t}$

$$
\begin{aligned}
& =r_{1}-r_{2}=k_{1 f} \theta_{C 6 H 1206(r) *} \theta_{*}-k_{1 r} \theta_{C 6 H 1106 *} \theta_{H *}-k_{2 f} \theta_{C 6 H 1106 *} \theta_{H *}+k_{2 r} \\
& \theta_{C 6 H 1206(o) *} \theta_{*}
\end{aligned}
$$

$\frac{d \theta_{C 6 H 1206(o) *}}{d t}=r_{2}=k_{2 f} \theta_{C 6 H 1106 *} \theta_{H *}-k_{2 r} \theta_{C 6 H 1206(o) *} \theta_{*}$

$\frac{d \theta_{H *}}{d t}$

$=r_{1}-r_{2}=k_{1 f} \theta_{C 6 H 1206(r) *} \theta_{*}-k_{1 r} \theta_{C 6 H 1106 *} \theta_{H *}-k_{2 f} \theta_{C 6 H 1106 *} \theta_{H *}+k_{2 r} \theta_{C 6 H 1206(o) *}$

$\theta_{*}$ 
$\theta_{C 6 H 1206(r) *}+\theta_{C 6 H 1106 *}+\theta_{C 6 H 1206(o) *}+\theta_{H *}+\theta_{*}=1$

16.2. Under HFUS conditions with surface $\mathrm{OH}^{*}$

We assume that initially under HFUS conditions, the $\mathrm{CuO}$ surface is fully covered with surface $\mathrm{OH}^{*}$ and adsorbed glucose in its ring-form. The elementary reactions network is:

$\mathrm{C}_{6} \mathrm{H}_{12} \mathrm{O}_{6}(\mathrm{r})^{*}+\mathrm{OH}^{*} \leftrightarrow \mathrm{C}_{6} \mathrm{H}_{11} \mathrm{O}_{6} *+\mathrm{H}_{2} \mathrm{O}^{*}$

$r_{1}=k_{1 f} \theta_{C 6 H 12 O 6(r) *} \theta_{O H *}-k_{1 r} \theta_{C 6 H 1106 *} \theta_{H 2 O *}$

$\mathrm{C}_{6} \mathrm{H}_{11} \mathrm{O}_{6} *+\mathrm{OH}^{*} \quad \leftrightarrow \mathrm{C}_{6} \mathrm{H}_{12} \mathrm{O}_{6}(\mathrm{o})^{*}+\mathrm{O}^{*}$

$r_{2 \_1}=k_{2_{1} 1_{f}} \theta_{C 6 H 1106 *} \theta_{O H *}-k_{2_{-} 1_{-} r} \theta_{C 6 H 12 O 6(o) *} \theta_{O *}$

$\mathrm{C}_{6} \mathrm{H}_{11} \mathrm{O}_{6} *+\mathrm{H}_{2} \mathrm{O}^{*} \leftrightarrow \mathrm{C}_{6} \mathrm{H}_{12} \mathrm{O}_{6}(\mathrm{o})^{*}+\mathrm{OH}^{*}$

$r_{2 \_}=k_{2 \_\_-f} \theta_{C 6 H 1106 *} \theta_{H 2 O *}-k_{2 \_2 \_} \theta_{C 6 H 12 O 6(o) *} \theta_{O H} *$

Therefore, on CuO-US during the reaction, the surface species include $\mathrm{OH}^{*}$ (initial coverage is assumed of $0.7 \mathrm{ML}$ ); $\mathrm{H}^{*} ; \mathrm{H}_{2} \mathrm{O}^{*}$ and three intermediates $\mathrm{C}_{6} \mathrm{H}_{12} \mathrm{O}_{6}(\mathrm{r}) *$ (adsorbed glucose with ring structure); $\mathrm{C}_{6} \mathrm{H}_{11} \mathrm{O}_{6} * \mathrm{C}_{6} \mathrm{H}_{12} \mathrm{O}_{6}$ (o)* (adsorbed glucose with open-chain structure). The ODE equations governing the surface coverages of species on $\mathrm{CuO}-\mathrm{US}$ are:

$\frac{d \theta_{C 6 H 1206(r) *}}{d t}=-r_{1}=-k_{1 f} \theta_{C 6 H 1206(r) *} \theta_{O H *}+k_{1 r} \theta_{C 6 H 1106 *} \theta_{H 2 O *}$

$\frac{d \theta_{C 6 H 1106 *}}{d t}$

$=r_{1}-r_{2 \_1}-r_{2 \_}=k_{1 f} \theta_{C 6 H 1206(r) *} \theta_{O H *}-k_{1 r} \theta_{C 6 H 1106 *} \theta_{H 2 O *}-k_{2 Z_{-}{ }_{-} f} \theta_{C 6 H 1106 *} *$ $\theta_{O H} * k_{2 \_1 r} \theta_{C 6 H 1206(o) * \theta_{O *}}-k_{2_{-} 2_{-} f} \theta_{C 6 H 1106 *} \theta_{H 2 O *}+k_{2_{-} 2_{-}} \theta_{C 6 H 12 O 6(o) *} \theta_{O H} *$

$\frac{d \theta_{H 2 O *}}{d t}$

$=r_{1}-r_{2 \_2}=k_{1 f} \theta_{C 6 H 12 O 6(r) *} \theta_{O H *}-k_{1 r} \theta_{C 6 H 1106 *} \theta_{H 2 O *}-k_{2 \_2 \_} \theta_{C 6 H 1106 *} \theta_{H 2 O *}+$

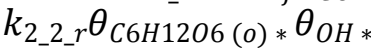

$\frac{d \theta_{O *}}{d t}=r_{2 \_1}=k_{2 \_1 \_} \theta_{C 6 H 1106 *} \theta_{O H *}-k_{2 \_1 \_} \theta_{C 6 H 1206(o) *} \theta_{O} *$

$\frac{d \theta_{C 6 H 1206(0) *}}{d t}$

$=r_{2 \_1}+r_{2 \_2}=k_{2 \_1 \_f} \theta_{C 6 H 1106 *} \theta_{O H *}-k_{2 \_\_1 r} \theta_{C 6 H 1206(0) *} \theta_{O *}+k_{2 \_2 \_f} \theta_{C 6 H 1106 *} *$

$\theta_{H 2 O *}-k_{2 \_}{ }_{-} r \theta_{C 6 H 12 O 6(o) *} \theta_{O H} *$

$\theta_{C 6 H 12 O 6(r) *}+\theta_{C 6 H 1106 *}+\theta_{C 6 H 12 O 6(o) *}+\theta_{O *}+\theta_{H 2 O *}+\theta_{O H *}=1$

16.3. Data for micro-kinetic modelling 
Using the Transition State Theory, (TST) ${ }^{30-31}$ all the rate coefficients $k_{r}$ and $k_{f}$ for reverse and forward elementary reactions can be calculated using the equation: $k=\frac{k_{B} T}{h} e^{\Delta G(T) / R T}$ at the reaction temperature $\mathrm{T}=80^{\circ} \mathrm{C}=353^{\circ} \mathrm{K}$, where $k_{B}$ and $h$ are the Boltzmann and Planck constant, respectively.

The free Gibbs activation energy $\Delta G(T)=E_{a}+\Delta Z P E-T \Delta S(T)+\Delta H_{c o r}(T)$, where $E_{a}$ is the activation barrier obtained from DFT calculations, and other components including Zero-point energy (ZPE), Entropy (S) and Enthalpy correction $\left(\mathrm{H}_{\text {cor }}\right)$ are obtained from statistical thermodynamic using vibration partition function computed from DFT. ${ }^{30-31}$ The data for microkinetic modelling at reaction temperature of $353 \mathrm{~K}$ are presented in Table $\mathrm{T} 6$.

Table T6. Free activation energies for forward $\left(\Delta \mathrm{G}_{\mathrm{f}}\right)$ and reverse $\left(\Delta \mathrm{G}_{\mathrm{r}}\right)$ reactions in the microkinetic modelling.

\section{Bare $\mathrm{CuO(111)}$ surface}

\begin{tabular}{ccc}
\hline & $\Delta G_{f}(\mathrm{~kJ} / \mathrm{mol})$ & $\Delta G_{r}(\mathrm{~kJ} / \mathrm{mol})$ \\
reaction 1 & 34.1 & 18.7 \\
reaction 2 & 37.8 & 4.6 \\
\hline & CuO-US surface (under HFUS conditions) \\
\hline reaction 1 & $\Delta G_{f}(\mathrm{~kJ} / \mathrm{mol})$ & $\Delta G_{r}(\mathrm{~kJ} / \mathrm{mol})$ \\
reaction 2_1 & 56.9 & 53.7 \\
reaction 2_2 & 185.7 & 5.2 \\
\hline
\end{tabular}

16.4. Results from micro-kinetic modelling. 
The ODE equations for glucose ring opening on bare $\mathrm{CuO}$ surface and on $\mathrm{CuO}-\mathrm{US}$ surface are solved using Matlab software with the solver oed23t due to its superior performance in curve continuity. The time step was auto-adjusted during the simulation. Assuming the initial coverages of adsorbed glucose (in ring structure) on bare $\mathrm{CuO}$ and $\mathrm{CuO}-\mathrm{US}$ surfaces are the same at $0.3 \mathrm{ML}$, we could study the time evolution coverage of glucose in its open chain structure (resulted from the ring-opening process) in Figure S14 under different conditions. It clearly shows that under HFUS, the formation of glucose open-chain structure is largely inhibited. The rate of glucose open-chain formation has been reduced to negligible levels compare to the reaction on bare $\mathrm{CuO}$ without the presence of surface $\mathrm{OH}$.

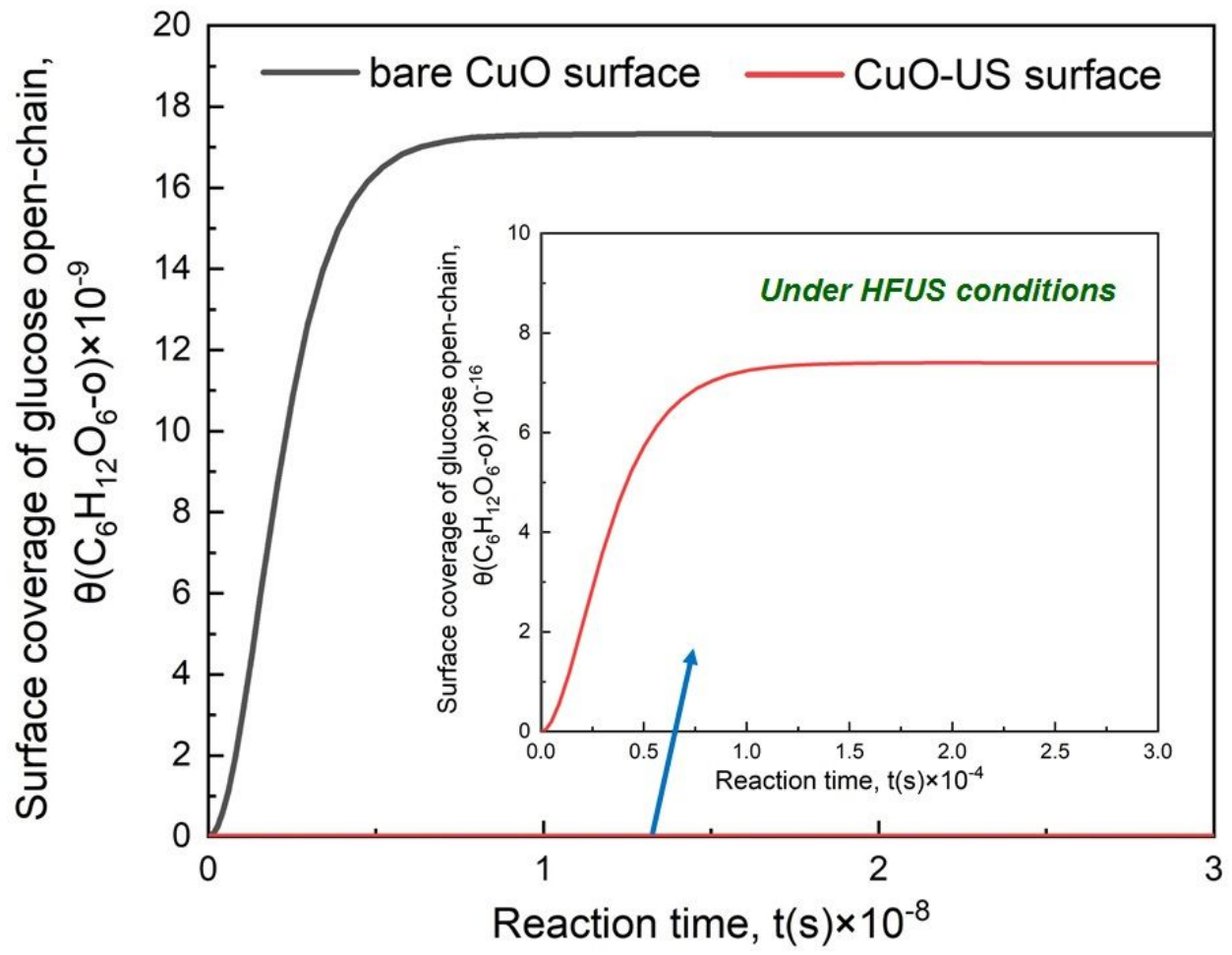

Figure S14. The surface coverages of glucose open-chain structure on bare $\mathrm{CuO}$ surface and on $\mathrm{CuO}$-US surface, assuming the same initial coverage of adsorbed glucose in its ring structure of $0.3 \mathrm{ML}$. Inserted picture shows the magnification of the red line (by factor of $10^{7}$ ) for the surface coverage of glucose open-chain on CuO-US (under HFUS conditions). 


\section{References:}

1. Tahir, D.; Tougaard, S., Electronic and optical properties of $\mathrm{Cu}, \mathrm{CuO}$ and $\mathrm{Cu}_{2} \mathrm{O}$ studied by electron spectroscopy. Journal of Physics: Condensed Matter 2012, 24 (17), 175002.

2. Svintsitskiy, D. A.; Kardash, T. Y.; Stonkus, O. A.; Slavinskaya, E. M.; Stadnichenko, A. I.; Koscheev, S. V.; Chupakhin, A. P.; Boronin, A. I., In Situ XRD, XPS, TEM, and TPR Study of Highly Active in CO Oxidation CuO Nanopowders. The Journal of Physical Chemistry C 2013, 117 (28), 14588-14599.

3. Singuru, R.; Trinh, Q. T.; Banerjee, B.; Govinda Rao, B.; Bai, L.; Bhaumik, A.; Reddy, B. M.; Hirao, H.; Mondal, J., Integrated Experimental and Theoretical Study of ShapeControlled Catalytic Oxidative Coupling of Aromatic Amines over $\mathrm{CuO}$ Nanostructures. ACS Omega 2016, 1 (6), 1121-1138.

4. Sarkar, C.; Pendem, S.; Shrotri, A.; Dao, D. Q.; Pham Thi Mai, P.; Nguyen Ngoc, T.; Chandaka, D. R.; Rao, T. V.; Trinh, Q. T.; Sherburne, M. P.; Mondal, J., Interface Engineering of Graphene-Supported $\mathrm{Cu}$ Nanoparticles Encapsulated by Mesoporous Silica for Size-Dependent Catalytic Oxidative Coupling of Aromatic Amines. ACS Applied Materials \& Interfaces 2019, 11 (12), 11722-11735.

5. Casella, I. G.; Gatta, M., Anodic electrodeposition of copper oxide/hydroxide films by alkaline solutions containing cuprous cyanide ions. Journal of Electroanalytical Chemistry 2000, 494 (1), 12-20.

6. Trinh, Q. T.; Bhola, K.; Amaniampong, P. N.; Jérôme, F.; Mushrif, S. H., Synergistic Application of XPS and DFT to Investigate Metal Oxide Surface Catalysis. The Journal of Physical Chemistry C 2018, 122 (39), 22397-22406.

7. Kresse, G.; Hafner, J., Ab initio molecular dynamics for liquid metals. Physical Review B 1993, 47 (1), 558-561.

8. Kresse, G.; Furthmüller, J., Efficiency of ab-initio total energy calculations for metals and semiconductors using a plane-wave basis set. Computational Materials Science 1996, 6 (1), 15-50.

9. Blöchl, P. E., Projector augmented-wave method. Physical Review B 1994, 50 (24), 17953 17979.

10. Perdew, J. P.; Burke, K.; Ernzerhof, M., Generalized Gradient Approximation Made Simple. Physical Review Letters 1996, 77 (18), 3865-3868.

11. Dudarev, S. L.; Botton, G. A.; Savrasov, S. Y.; Humphreys, C. J.; Sutton, A. P., Electronenergy-loss spectra and the structural stability of nickel oxide: An LSDA+U study. Physical Review B 1998, 57 (3), 1505-1509.

12. Anisimov, V. I.; Zaanen, J.; Andersen, O. K., Band theory and Mott insulators: Hubbard U instead of Stoner I. Physical Review B 1991, 44 (3), 943-954.

13. Amaniampong, P. N.; Trinh, Q. T.; Wang, B.; Borgna, A.; Yang, Y.; Mushrif, S. H., Biomass Oxidation: Formyl C-H Bond Activation by the Surface Lattice Oxygen of Regenerative $\mathrm{CuO}$ Nanoleaves. Angewandte Chemie International Edition 2015, 54 (31), 8928-8933.

14. Hu, J.; Li, D.; Lu, J. G.; Wu, R., Effects on Electronic Properties of Molecule Adsorption on $\mathrm{CuO}$ Surfaces and Nanowires. The Journal of Physical Chemistry C 2010, 114 (40), 17120-17126. 
15. Henkelman, G.; Uberuaga, B. P.; Jónsson, H., A climbing image nudged elastic band method for finding saddle points and minimum energy paths. The Journal of Chemical Physics 2000, 113 (22), 9901-9904.

16. Trinh, Q. T.; Nguyen, A. V.; Huynh, D. C.; Pham, T. H.; Mushrif, S. H., Mechanistic insights into the catalytic elimination of tar and the promotional effect of boron on it: firstprinciples study using toluene as a model compound. Catalysis Science \& Technology 2016, 6 (15), 5871-5883.

17. Grimme, S.; Antony, J.; Ehrlich, S.; Krieg, H., A consistent and accurate ab initio parametrization of density functional dispersion correction (DFT-D) for the 94 elements $\mathrm{H}-\mathrm{Pu}$. The Journal of Chemical Physics 2010, 132 (15), 154104.

18. Grimme, S.; Ehrlich, S.; Goerigk, L., Effect of the damping function in dispersion corrected density functional theory. Journal of Computational Chemistry 2011, 32 (7), 1456-1465.

19. Bhola, K.; Varghese, J. J.; Dapeng, L.; Liu, Y.; Mushrif, S. H., Influence of Hubbard U Parameter in Simulating Adsorption and Reactivity on $\mathrm{CuO}$ : Combined Theoretical and Experimental Study. The Journal of Physical Chemistry C 2017, 121 (39), 21343-21353.

20. Amaniampong, P. N.; Trinh, Q. T.; Varghese, J. J.; Behling, R.; Valange, S.; Mushrif, S. H.; Jérôme, F., Unraveling the mechanism of the oxidation of glycerol to dicarboxylic acids over a sonochemically synthesized copper oxide catalyst. Green Chemistry 2018, 20 (12), $2730-2741$.

21. Trinh, Q. T.; Chethana, B. K.; Mushrif, S. H., Adsorption and Reactivity of Cellulosic Aldoses on Transition Metals. The Journal of Physical Chemistry C 2015, 119 (30), 1713717145.

22. Schenck, F. W., Glucose and Glucose-Containing Syrups. In Ullmann's Encyclopedia of Industrial Chemistry, 2006.

23. Mushrif, S. H.; Varghese, J. J.; Vlachos, D. G., Insights into the Cr(III) catalyzed isomerization mechanism of glucose to fructose in the presence of water using ab initio molecular dynamics. Physical Chemistry Chemical Physics 2014, 16 (36), 19564-19572.

24. Bermejo-Deval, R.; Assary, R. S.; Nikolla, E.; Moliner, M.; Román-Leshkov, Y.; Hwang, S.-J.; Palsdottir, A.; Silverman, D.; Lobo, R. F.; Curtiss, L. A.; Davis, M. E., Metalloenzyme-like catalyzed isomerizations of sugars by Lewis acid zeolites. Proceedings of the National Academy of Sciences 2012, 109 (25), 9727-9732.

25. Qian, X., Free Energy Surface for Brønsted Acid-Catalyzed Glucose Ring-Opening in Aqueous Solution. The Journal of Physical Chemistry B 2013, 117 (39), 11460-11465.

26. Assary, R. S.; Curtiss, L. A., Comparison of Sugar Molecule Decomposition through Glucose and Fructose: A High-Level Quantum Chemical Study. Energy \& Fuels 2012, 26 (2), 1344-1352.

27. Amaniampong, P. N.; Trinh, Q. T.; Li, K.; Mushrif, S. H.; Hao, Y.; Yang, Y., Porous structured $\mathrm{CuO}-\mathrm{CeO} 2$ nanospheres for the direct oxidation of cellobiose and glucose to gluconic acid. Catalysis Today 2018, 306, 172-182.

28. Varghese, J. J.; Trinh, Q. T.; Mushrif, S. H., Insights into the synergistic role of metallattice oxygen site pairs in four-centered $\mathrm{C}-\mathrm{H}$ bond activation of methane: the case of $\mathrm{CuO}$. Catalysis Science \& Technology 2016, 6 (11), 3984-3996. 
29. Gunasooriya, G. T. K. K.; van Bavel, A. P.; Kuipers, H. P. C. E.; Saeys, M., Key Role of Surface Hydroxyl Groups in $\mathrm{C}-\mathrm{O}$ Activation during Fischer-Tropsch Synthesis. ACS Catalysis 2016, 6 (6), 3660-3664.

30. Irikura, K. K., Appendix B. In Computational Thermochemistry, American Chemical Society: 1998; Vol. 677, pp 402-418.

31. Nørskov, J. K.; Studt, F.; Abild-Pedersen, F.; Bligaard, T., Rate Constants. In Fundamental Concepts in Heterogeneous Catalysis, Nørskov, J. K.; Studt, F.; Abild-Pedersen, F.; Bligaard, T., Eds. 2014. 